\title{
RGD-decorated cholesterol stabilized polyplexes for targeted siRNA delivery to glioblastoma cells
}

\author{
Bo Lou ${ }^{1} \cdot$ Kate Connor ${ }^{2} \cdot$ Kieron Sweeney $^{2,3} \cdot \operatorname{lan}$ S. Miller ${ }^{2} \cdot$ Alice O'Farrell $^{2} \cdot$ Eduardo Ruiz-Hernandez $^{4}$. \\ David M. Murray ${ }^{2} \cdot$ Garry P. Duffy $^{5} \cdot$ Alan Wolfe $^{6} \cdot$ Enrico Mastrobattista $^{1} \cdot$ Annette T. Byrne $^{2} \cdot$ Wim E. Hennink $^{1}$
}

Published online: 9 April 2019

(C) The Author(s) 2019

\begin{abstract}
The development of an effective and safe treatment for glioblastoma (GBM) represents a significant challenge in oncology today. Downregulation of key mediators of cell signal transduction by RNA interference is considered a promising treatment strategy but requires efficient, intracellular delivery of siRNA into GBM tumor cells. Here, we describe novel polymeric siRNA nanocarriers functionalized with cRGD peptide that mediates targeted and efficient reporter gene silencing in U87R invasive human GBM cells. The polymer was synthesized via RAFT copolymerization of N-(2-hydroxypropyl)-methacrylamide (HPMA) and $\mathrm{N}$-acryloxysuccinimide (NAS), followed by post-polymerization modification with cholesterol for stabilization, cationic amines for siRNA complexation, and azides for copper-free click chemistry. The novel resultant cationic polymer harboring a terminal cholesterol group, self-assembled with siRNA to yield nanosized polyplexes $(\sim 40 \mathrm{~nm})$ with good colloidal stability at physiological ionic strength. Post-modification of the preformed polyplexes with PEG-cRGD end-functionalized with bicyclo[6.1.0]nonyne $(\mathrm{BCN})$ group resulted in enhanced cell uptake and increased luciferase gene silencing in U87R cells, compared to polyplexes lacking cRGD-targeting groups.
\end{abstract}

Keywords Cancer targeting $\cdot$ siRNA delivery $\cdot$ Glioblastoma $\cdot$ cRGD peptide $\cdot$ Cholesterol modification

Annette T. Byrne and Wim E. Hennink are Joint Senior Authors.

Bo Lou and Kate Connor contributed equally to this work.

Electronic supplementary material The online version of this article (https://doi.org/10.1007/s13346-019-00637-y) contains supplementary material, which is available to authorized users.

Wim E. Hennink

W.E.Hennink@uu.nl

1 Department of Pharmaceutics, Utrecht Institute for Pharmaceutical Sciences, Utrecht University, 3584 CG Utrecht, The Netherlands

2 Department of Physiology and Medical Physics, Royal College of Surgeons in Ireland, York Street, Dublin 2, Ireland

3 Department of Neurosurgery, Beaumont Hospital, Dublin, Ireland

4 School of Pharmacy and Pharmaceutical Sciences, Trinity College Dublin, Dublin, Ireland

5 Anatomy, School of Medicine, College of Medicine Nursing and Health Sciences, National University of Ireland, Galway, Ireland

6 UCD School of Veterinary Medicine, Belfield Dublin, Ireland

\section{Introduction}

GBM is the most common malignant brain tumor in adults and is an incurable disease characterized by rapid tumor growth, neovascularization, and aggressive invasion throughout the brain [1]. The standard of care (SOC) for GBM is maximal safe surgical resection followed by radiation therapy with concomitant and adjuvant temozolomide (TMZ) delivered via the established "Stupp protocol" [2]. Notwithstanding, patients diagnosed with GBM have a devastatingly low median life expectancy of $<2$ years, with SOC treatment remaining largely palliative. There is therefore an urgent need for new therapeutic modalities.

The RNA interference (RNAi) is an established therapeutic approach based on the delivery of small interfering RNAs (siRNAs) into target cells to induce sequence-specific gene silencing. While RNAi has significant potential as a therapeutic strategy in oncology [3, 4], the therapeutic utility of "unpackaged" siRNAs is limited due to their intrinsic instability and poor delivery into target tissues. Moreover, delivery in the setting of GBM is further limited by the poor penetration of drugs into the tumor due to the presence of the blood-brain and 
blood-tumor barriers. Targeting of integrins has been demonstrated to be a rational approach to circumvent these delivery and penetration issues. These proteins are key mediators in GBM cell growth, invasion, and angiogenesis with $\mathrm{a}_{\mathrm{v}} \beta_{3}$ and $\mathrm{a}_{\mathrm{v}} \beta_{5}$ integrin family receptors further overexpressed on the endothelial cells of tumor vessels. Cylic Arg-Gly-Asp motifs (cRGD) bind to these integrins and thus allows selective targeting. To date, several studies have demonstrated the utility of an RGD-based targeting strategy in the GBM setting [5].

To effectively implement RNAi as a strategy in the treatment of GBM, an effective biodegradable delivery system is essential. To this end, a number of cationic polymers have been employed for siRNA delivery, including poly(ethylene imine), [6] poly(1-lysine), [7] poly(amido amine)s [8], and $\mathrm{N}$-(2-hydroxypropyl)-methacrylamide (HPMA)-based cationic polymers [9-11]. Moreover, poly(N-(2-hydroxypropyl)methacrylamide) (pHPMA) has been approved for clinical use following demonstration of a favorable safety profile $[12,13]$. A pHPMA derivative-p(HPMA-DMAE) has further been studied for gene delivery in ovarian cancers having the advantage of intrinsic degradable properties [14] and low cytotoxicity [15]. However, an inherent problem with positively charged siRNA polyplexes is the tendency to aggregate or dissociate upon interaction with serum proteins, leading to premature siRNA release in vitro [16-18]. Currently, PEGylation of gene delivery carriers is the typical approach to improve stability and pharmacokinetic profiles [19]. The most common strategy involves the direct introduction of PEG into the synthetic polymer chains as diblock or graft copolymer. However, the presence of PEG during complexation may influence the nucleic acid complexation and condensation capacity as well as size and morphology of formed nanoparticles, due to the anti-compaction force from PEG steric repulsion [20-22]. One alternative strategy involves post-PEGylation of the desired polyplexes, with several studies showing that this method can increase stability in vivo [23-25]. However, the presence of a PEG corona covering the surface of polyplexes also has drawbacks; it inhibits cellular uptake and endosomal escape of the siRNA complexes, potentially leading to a substantial decrease in the genesilencing efficiency [26]. One method to resolve this (PEG) dilemma is the linking of PEG to the siRNA complexes via disulfide bonds, enabling PEG detachment from the siRNA complex in response to changes in environmental redox potential $[27,28]$. To further increase the stability of PEGylated siRNA polyplexes, additional sophisticated approaches have been explored including disulfide cross-linking [29], quaternary amines [30,31], and hydrophobic interactions [20, 28, 32]. In particular, hydrophobic moieties, e.g., cholesterol, can assist the spontaneous assembly of polyplexes through hydrophobic interactions in aqueous solutions, rendering polyplexes more resistant to dissociation, eventually leading to a long longer circulation times in vivo $[7,33]$.
To circumvent the many challenges discussed above, we have designed and implemented a novel polymeric siRNA nanocarrier functionalized with cRGD peptide to facilitate GBM cellular uptake and mediate efficient reporter gene silencing. Herein, we describe the synthesis, characterization, and utility of $\omega$-cholesteryl p(HPMA-r-NAS) polymers containing the reactive group NAS using RAFT polymerization. Cholesterol conjugation was performed by heating the polymer in the presence of a cholesterol-modified radical initiator, to form a stable group at the $\omega$ chain-end. After polymerization, the NAS groups of the polymer were modified with reducible azide groups containing disulfide bonds. HPMA groups were further derivatized with a cationic group (N, $\mathrm{N}^{\prime}$-dimethylaminoethanol, DMAE) coupled to the secondary hydroxyl group of HPMA via a hydrolysable carbonate ester. The resulting polymers formed small siRNA polyplexes through both polycation electrostatic interaction and siRNA and hydrophobic interaction via cholesterol. Subsequently, these polyplexes were post-modified with PEG-cRGD modified with bicyclo[6.1.0]nonyne $(\mathrm{BCN})$ using copper-free click chemistry to shield surface charge and enable ligand-mediated cell binding and uptake [25, 34]. In vitro experiments showed enhanced cellular uptake of PEG-cRGD modified polyplexes, which in turn resulted in improved transfection efficiency as compared to non-PEGylated particles.

\section{Materials and methods}

\section{Materials}

N-(2-hydroxypropyl) methacrylamide (HPMA) [35], 2-(dimethylamino)ethyl ${ }^{1} \mathrm{H}$-imidazole-1-carboxylate (DMAE-CI) [14], and imidazole-1-sulfonyl azide hydrochloride [36] were synthesized as previously described. Azobis(isobutyronitrile) (AIBN), 4,4'-azobis (N,N'-cyanopentanoic acid) (V501), cholesterol, dicyclohexylcarbodiimide (DCC), 4-(dimethylamino)pyridine (DMAP), and all other reagents and solvents used in the synthesis were obtained from Sigma-Aldrich and were used without further purification. 2,5-Dioxopyrrolidin-1-yl 4-((((1R,8S,9s)bicyclo[6.1.0] non-4-yn-9-ylmethoxy)carbonyl)amino)butanoate (BCN, SX-A1036) was purchased from Synaffix BV (Oss, The Netherlands). cRGD-azide was provided by ChinaPeptides Co.,Ltd. (Shanghai, China). Agarose multi-purpose was purchased from Roche Molecular Biochemicals (Mannheim, Germany). Six times DNA Loading Dye was purchased from Fermentas (St. Leon-Roth, Germany). SYBR Safe DNA gel stain, lipofectamine 2000, DEME/F12 medium, Opti-MEM, G418, and heatinactivated fetal bovine serum (HI-FBS) were purchased from Life Technologies (Breda, The Netherlands). Luc2 siRNA targeted for luc2 luciferase, scrambled siRNA (siCon), and a Cy5-labeled Luc2 siRNA were obtained from Dharmacon, Inc. (Eindhoven, The Netherlands). The 
sequence of the sense strand of the Luc2 siRNA is 5'GGACGAGGACGAGCACUUCUU- ${ }^{\prime}$ and the antisense strand sequence is $3^{\prime}$-UUCCUGCUCCUGCUCGUGAAG-5'. The Cy5 fluorophore within the Cy5-labeled Luc2 siRNA was conjugated to the 3 ' terminus of the anti-sense strand.

\section{Synthesis of monomers}

\section{Synthesis of cholesteryl V501 derivative $\left(\mathrm{C}-\mathrm{V}_{501}-\mathrm{C}\right)$}

The procedure as shown in Fig. 1a was used to synthesize C$\mathrm{V}_{501}{ }^{-C}$. DCC (4.85 g, $\left.23.5 \mathrm{mmol}\right)$ was dissolved in dry DCM $(100 \mathrm{~mL})$ and stirred in an ice water bath under an argon atmosphere. Next, V501 (3.00 g, $10 \mathrm{mmol})$ and DMAP $(0.29 \mathrm{~g}, 2.35 \mathrm{mmol})$ were added and the mixture was stirred for $5 \mathrm{~min}$ followed by the addition of cholesterol $(8.25 \mathrm{~g}$, $21.3 \mathrm{mmol}$ ). After $4 \mathrm{~h}$, the ice water bath was removed, and the solution was kept at room temperature for $16 \mathrm{~h}$ and then filtered to remove the solids. DCM was removed under reduced pressure, and the crude product was dissolved in DCM and purified by silica gel chromatography with DCM as eluent yielding $\mathrm{C}-\mathrm{V}_{501}-\mathrm{C}$ as a white solid in $45 \%$ overall yield $\left(4.80 \mathrm{~g}, R_{\mathrm{f}}=0.47\right)$. The monomer was characterized by ATR-IR and ${ }^{1} \mathrm{H}$ NMR (400 MHz, $\mathrm{CDCl}_{3}$ ) (Fig. S1).

\section{Synthesis of 2-((2-azidoethyl) disulfanyl) ethan-1-amine hydrochloride}

The synthesis procedures were similar as previously published with slight modifications (Scheme S1) [36]. Typically,

a)

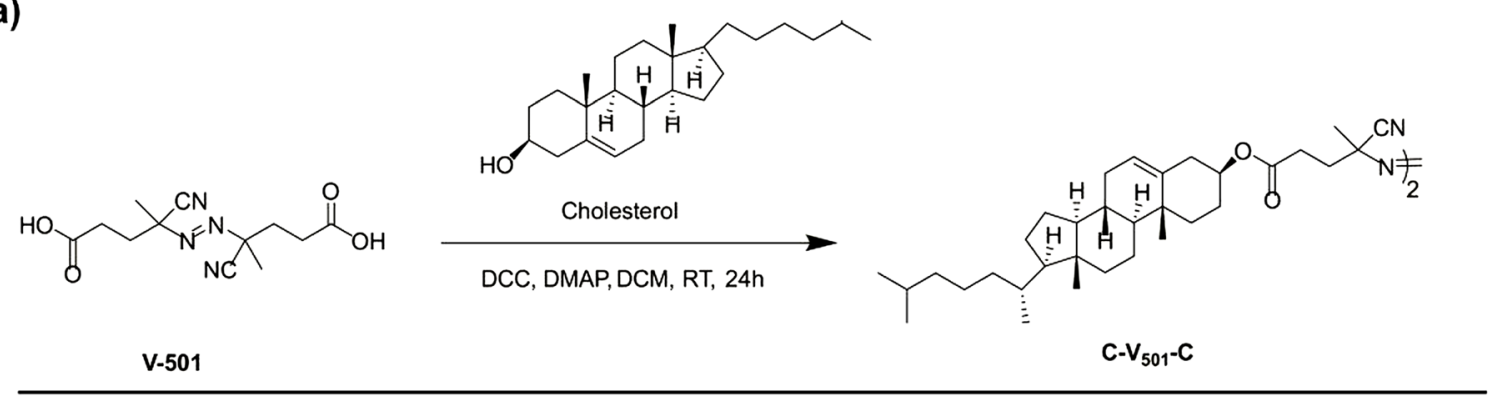

b)

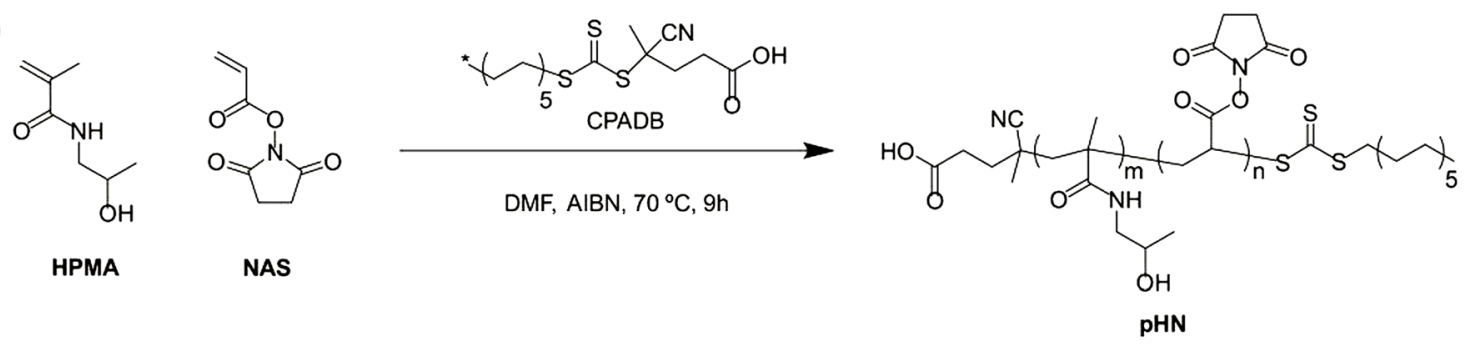

c)
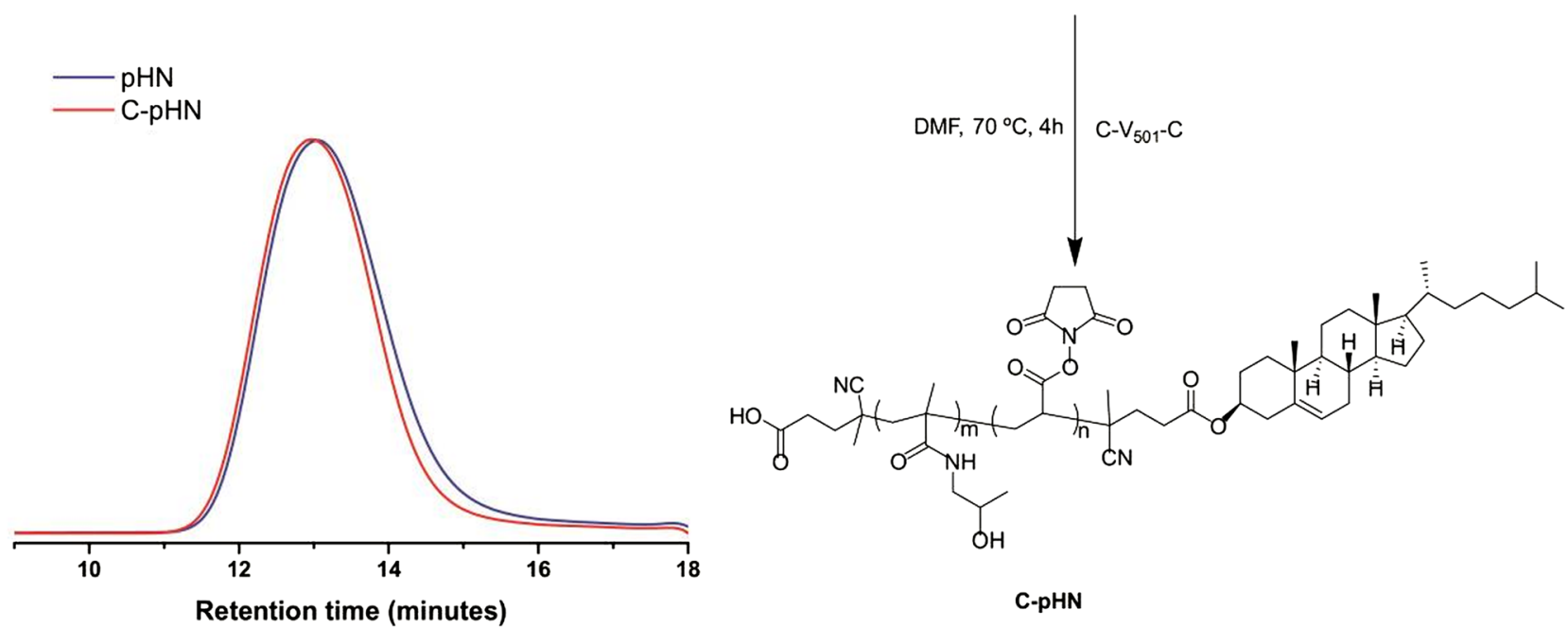

Fig. 1 a Synthesis of cholesteryl V501 derivative $\left(\mathrm{C}-\mathrm{V}_{501}-\mathrm{C}\right)$; b synthesis of cholesteryl p(HPMA-r-NAS) (C-pHN); c GPC traces of pHN (blue) and C$\mathrm{pHN}$ (red) 
cystamine dihydrochloride salt $(3.22 \mathrm{~g}, 14.3 \mathrm{mmol}), \mathrm{K}_{2} \mathrm{CO}_{3}$ $(6.00 \mathrm{~g}, 43.4 \mathrm{mmol})$, and $\mathrm{CuSO}_{4} .5 \mathrm{H}_{2} \mathrm{O}(35.73 \mathrm{mg}$, $143.1 \mu \mathrm{mol})$ were dissolved in methanol $(60 \mathrm{~mL})$. Imidazole-1-sulfonyl azide hydrochloride ( $3.00 \mathrm{~g}, 14.3 \mathrm{mmol}$ ) was added to the suspension and the mixture was stirred at room temperature for $12 \mathrm{~h}$. Next, the mixture was concentrated by evaporation of the solvent under reduced pressure, diluted with $\mathrm{H}_{2} \mathrm{O}(180 \mathrm{~mL})$, and extracted with DCM $(3 \times$ $120 \mathrm{~mL})$. The combined organic layers were dried $\left(\mathrm{MgSO}_{4}\right)$, filtered, and concentrated. Silica gel flash chromatography gave yellow waxy solids (DCM/MeOH/ $\mathrm{NH}_{4} \mathrm{OH}, 50: 2: 1-$ $80: 20: 1)$, the yield was $0.80 \mathrm{~g}\left(32 \%, R_{\mathrm{f}}=0.5\right)$. The monomer was characterized by ATR-IR and NMR $\delta{ }^{1} \mathrm{H}$ NMR (400 MHz, DMSO-d ${ }_{6}$ ) (Fig. S3).

\section{Polymer synthesis}

\section{Synthesis of BCN-PEG and BCN-PEG-CRGD}

$\mathrm{NH}_{2}-\mathrm{PEG}_{5000}-\mathrm{COOH}$ (100 mg, $0.02 \mathrm{mmol}, 1$ equiv.), cyclooctyne-NHS (BCN-NHS; $9.0 \mathrm{mg}, 0.024 \mathrm{mmol}, 1.2$ equiv.), and triethylamine ( $8.5 \mu \mathrm{L}, 0.06 \mathrm{mmol}, 3$ equiv.) were dissolved in $1.3 \mathrm{~mL} \mathrm{DMSO}$; the reaction mixture was stirred at room temperature overnight. The final product was precipitated in cold ether twice, then dissolved in milliQ water, followed by dialysis against water (MWCO 3000, Merck Millipore, Germany) for 2 days. After filtration and freezedrying, the BCN-PEG-COOH (BCN-PEG) was obtained as a white powder $(90 \mathrm{mg}, 85.7 \%) .{ }^{1} \mathrm{H}$ NMR $(400 \mathrm{MHz}$, DMSO): $\delta=7.05(\mathrm{~s}, 1 \mathrm{H} ; \mathrm{OC}(=\mathrm{O}) \mathrm{NH}), 7.05(\mathrm{~s}, 1 \mathrm{H} ; \mathrm{C}=\mathrm{ONH})$, 4.52 (t, 2H; PEG-OH), 4.00 (d, 2H; $\left.\mathrm{BCN}_{-} \mathrm{CH}_{2}-\mathrm{O}(=\mathrm{O})\right), 3.66$ (t, 2H; PEG-CH $_{2}$ ), 3.48 (bs, 440H; PEG), 3.04 (s, 2H; $\left.\mathrm{OCONHCH}_{2}\right), 2.90$ (s, $\left.2 \mathrm{H} ; \mathrm{C}=\mathrm{ONHCH}_{2}\right), 2.0-2.21(\mathrm{~m}, 4 \mathrm{H}$; $\mathrm{CH}_{2} \mathrm{C}(=\mathrm{O}) \mathrm{NH}_{2}$, alkane), 1.99 (m, $\left.2 \mathrm{H} ; \mathrm{NHCH}_{2} \mathrm{CH}_{2}\right), 1.69$ 1.41 (m, 6H; alkane), 1.54-1.13 (m, 1H; alkane), 0.80-0.71 (m, $2 \mathrm{H}$; alkane).

To a solution of $\mathrm{NH}_{2}-\mathrm{PEG}_{6000}-\mathrm{NH}_{2}(300 \mathrm{mg}, 0.05 \mathrm{mmol})$ in DMSO (1.5 mL), cyclooctyne-NHS (BCN-NHS $75.3 \mathrm{mg}$, $0.2 \mathrm{mmol}, 4$ equiv.), and trimethylamine ( $41.8 \mu \mathrm{L}, 0.3 \mathrm{mmol}, 6$ equiv.) were added. The solution was subsequently stirred for $16 \mathrm{~h}$ at room temperature. Next, the solution was dropped into cold ether twice to precipitate the formed product. The precipitate was subsequently dissolved in $10 \mathrm{~mL}$ water and dialyzed against water using a membrane with a molecular weight cut off of 3000 for 2 days. After filtration and freeze-drying, BCN-PEG-BCN was obtained as a white powder $(270 \mathrm{mg}, 85.7 \%)$. Then, BCNPEG-BCN $(41.6 \mathrm{mg}, 6.41 \mu \mathrm{mol})$ was dissolved in $1 \mathrm{~mL}$ dry DMSO, followed by the addition of cylic RGD-azide $(4.0 \mathrm{mg}$, $6.41 \mu \mathrm{mol})$; the obtained solution was stirred for $16 \mathrm{~h}$ at room temperature. Next, $10 \mathrm{~mL}$ water was added and the product was obtained after freeze-drying. Subsequently, the product was dissolved in $5 \mathrm{~mL}$ water and dialyzed against water for 2 days using a membrane with a molecular weight cut off of 3000 . The product was obtained in a yield of $90 \%$. The amount of cRGD conjugated to $\mathrm{BCN}-\mathrm{PEG}-\mathrm{BCN}$ was determined using ${ }^{1} \mathrm{H}$ NMR analysis based on the peak intensity ratio of phenyl protons of the cRGD peptide (7.0-7.2 ppm) to ethylene protons of PEG $\left(-\mathrm{CH}_{2}-\mathrm{CH}_{2}\right.$, 3.4-3.6 ppm) (Fig. S6). The product was analyzed by SEC (Fig. S7) and the shift of the PEG peak to a slightly shorter retention time proved that a product with higher molecular weight was obtained and thus showed the successful conjugation of cRGD and BCN-PEG. It should be noted that the applied procedure resulted in the formation of a mixture of BCN-PEG-cRGD, cRGD-PEG-cRGD, and unreacted BCN-PEG-BCN.

\section{Synthesis of $p$ (HPMA-r-NAS) (pHN) by RAFT polymerization}

p(HPMA-r-NAS) was synthesized by reversible addition fragmentation chain transfer (RAFT) copolymerization as previously published [37]. Briefly, 4-cyano4-[(dodecylsulfanylthiocarbonyl)-sulfanyl] pentanoic acid (CDTPA) was used as a chain transfer agent (CTA), and AIBN as initiator (I). The polymer was synthesized using monomers (HPMA/NAS) to chain transfer agent and initiator ratio (monomers/CTA/I) of 100/1/0.1 (mol/ $\mathrm{mol} / \mathrm{mol})$ and feed ratio HPMA/NAS of 70/30 (mol/ mol). 1,3,5-Trioxane was added as internal NMR standard with a final concentration of $0.1 \mathrm{M}$. After purging the solution with argon for half an hour, the polymerization was carried at $70{ }^{\circ} \mathrm{C}$ for $9 \mathrm{~h}$ in dry DMF under argon, using a final monomer concentration of $1.0 \mathrm{M}$. After polymerization, the conversion of the monomers was analyzed by ${ }^{1} \mathrm{H}$ NMR spectroscopy by dilution a sample of the reaction mixture 10 times with DMSO- $\mathrm{d}_{6}$. The synthesized polymer was precipitated into a mixture of anhydrous acetone and diethyl ether $(50 / 50, v / v)$. The procedure was repeated for three times and the product was dried in vacuo prior to ${ }^{1} \mathrm{H}$ NMR and GPC analysis (yield 60\%). The theoretical molecular weight was calculated as follows: $M_{\mathrm{n}}($ theory $)=[$ monomer $] /$ $[\mathrm{CTA}] \times\left(\right.$ conversion $($ HPMA $) \times M_{\mathrm{w}(\text { HPMA })} \times 0.7+$ conversion $\left._{(\mathrm{NAS})} \times M_{\mathrm{w}(\mathrm{NAS})} \times 0.3\right)+M_{\mathrm{wCTA}}$, the ratio of [monomer]/[CTA] was $100 .{ }^{1} \mathrm{H}$ NMR $(400 \mathrm{MHz}$, DMSO-d ${ }_{6}$ ); $\delta \mathrm{ppm}$ 0.95-1.52 (backbone- $\mathrm{CH}_{3}$, $\mathrm{CH}_{3} \mathrm{CH}(\mathrm{OH})$ ), 1.55-2.41 (backbone $\mathrm{CH}_{2}$, backbone$\mathrm{CH}), 3.00-3.33\left(\mathrm{CH}_{2} \mathrm{NH}\right), 3.5\left(\mathrm{NHS}-\mathrm{CH}_{2}\right)$, and 3.90 $(\mathrm{CHOH})$ (Fig. 2b).

\section{Radical cross-coupling of pHN with $\mathrm{C}-\mathrm{V}_{501}-\mathrm{C}(\mathrm{C}-\mathrm{pHN})$}

The reaction process was based on previously published methods [38]. p(HPMA-r-NAS) $(400 \mathrm{mg}, 40.5 \mu \mathrm{mol}$, calculated based on the $M_{\mathrm{n}}$ (theory) $=9800 \mathrm{~g} / \mathrm{mol}$ ) and C-V501-C (1238 mg, $1217 \mu \mathrm{mol}$ ) were dissolved in $4 \mathrm{~mL}$ dry DMF, and the solution purged with argon for $30 \mathrm{~min}$. Subsequently, the flask was put into the preheated oil bath $\left(70^{\circ} \mathrm{C}\right)$ and incubated 
Fig. $2{ }^{1} \mathrm{H}$ NMR (DMSO-D $)$ spectra of C-pHN (a) and pHN (b)

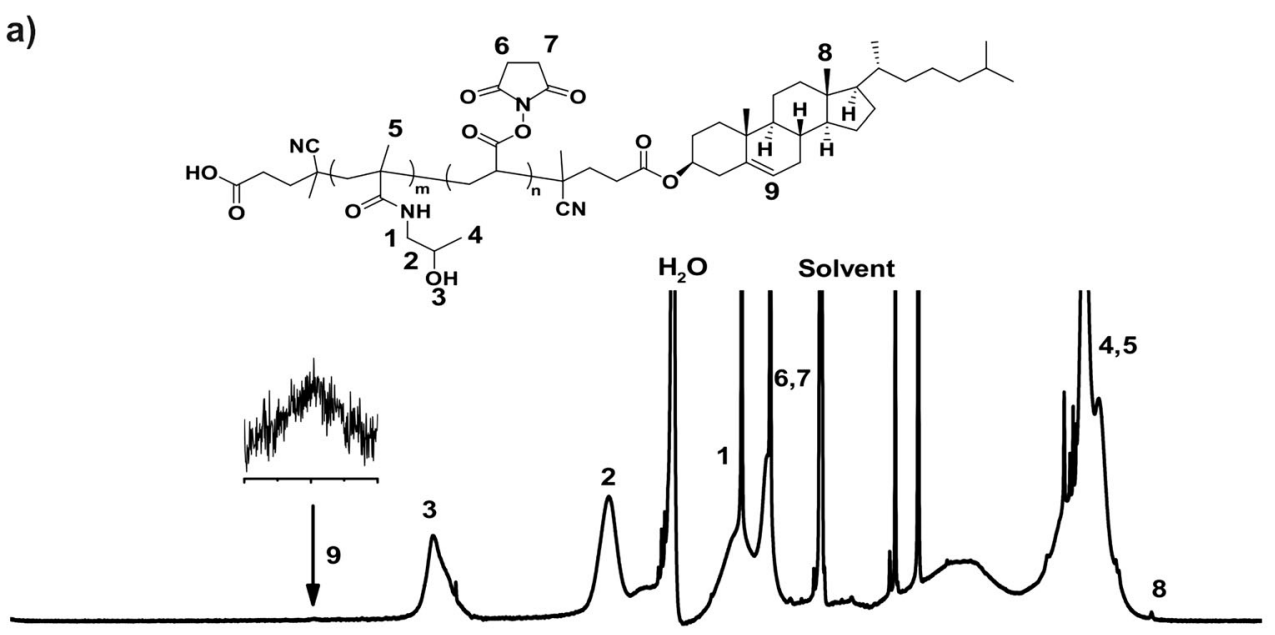

b)

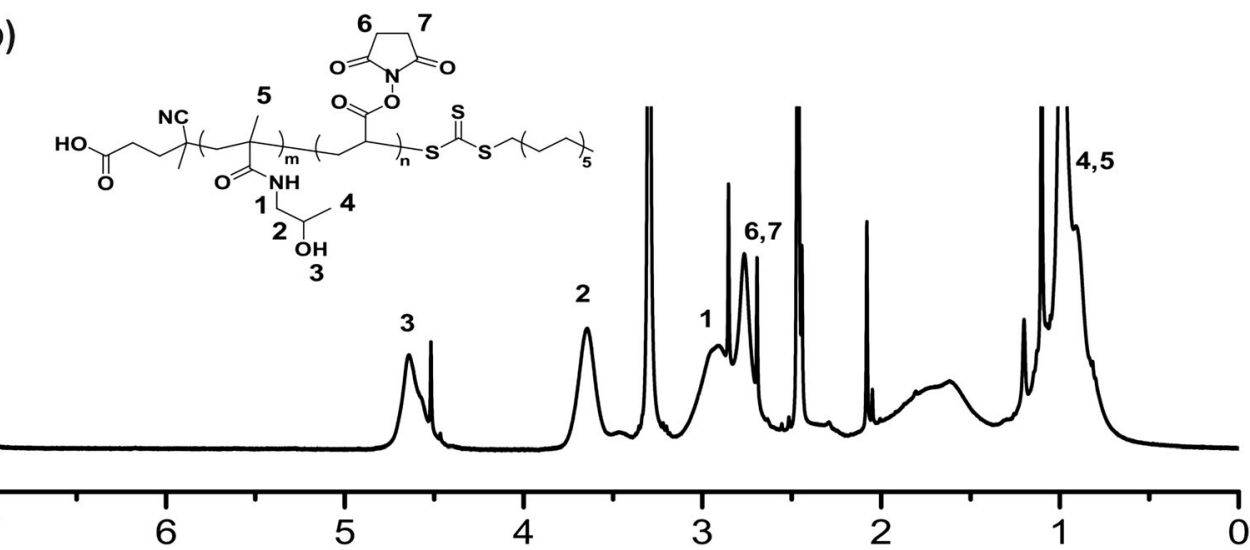

for $4 \mathrm{~h}$. A control polymer without cholesterol modification was synthesized as follows: p(HPMA-r-NAS) $(100 \mathrm{mg}$, $10.1 \mu \mathrm{mol}$, calculated based on the $M_{\mathrm{n}}$ (theory) $=9800 \mathrm{~g} /$ mol) and AIBN (50 mg, $304 \mu \mathrm{mol}$ ) were dissolved in $1 \mathrm{~mL}$ dry DMF and heated at $70{ }^{\circ} \mathrm{C}$ for $4 \mathrm{~h}$ under an argon atmosphere. The product was precipitated two times in a mixture of anhydrous acetone and diethyl ether $(50 / 50, v / v)$, dried in vacuo prior to ${ }^{1} \mathrm{H}$ NMR and GPC analysis (yield 65\%).

\section{Synthesis of cholesteryl p(HPMA-DMAE-r-AEDA) (C-pHDA)}

The cholesteryl copolymer (C-pHN, $300 \mathrm{mg})(0.56 \mathrm{mmol}$ of NAS, 1.44 mmol of HPMA) was dissolved in $3 \mathrm{~mL}$ dry DMSO and flushed with argon for $30 \mathrm{~min}$. Next, $72 \mathrm{mg}(0.40 \mathrm{mmol})$ of 2-((2-azidoethyl) disulfanyl) ethan-1-amine hydrochloride (AEDA) was added to this solution under argon purge. Then, $340 \mathrm{mg}(3.36 \mathrm{mmol})$ of triethylamine was injected into the reaction vessel and the solution was stirred at $35{ }^{\circ} \mathrm{C}$. After $48 \mathrm{~h}, 84 \mathrm{mg}$ (1.2 mmol) of d,l-amino-2-propanol was injected into the reaction mixture and the solution was stirred for $16 \mathrm{~h}$ at room temperature. The modified polymer was precipitated twice into a mixture of anhydrous acetone and diethyl ether (50/50) and dried in vacuo to get the white-colored product C-pHNA (yield 63\%). The resulting polymer was then dissolved in $2 \mathrm{~mL}$ dry DMSO. DMAE-CI ( $3.4 \mathrm{~g}, 14.4 \mathrm{mmol}$ ) was added and the solution was flushed with argon. After $72 \mathrm{~h}$ of reaction at room temperature, the solution was diluted with $20 \mathrm{ml}$ of $5 \mathrm{mM}$ ammonium acetate buffer ( $\mathrm{pH} 5$ ) and purified with the same buffer by ultrafiltration for $24 \mathrm{~h}$ using a membrane with MWCO of 3000 . The resulting polymer solution was filtered with $0.2-\mu \mathrm{m}$ filter and the polymer was obtained after freeze-drying (yield $94.7 \mathrm{mg}$ ).

\section{Characterization of polymer}

The copolymer composition of the different polymers was determined by ${ }^{1} \mathrm{H}$ NMR analysis performed with a Gemini $400 \mathrm{MHz}$ spectrometer (Varian Associates Inc., NMR Instruments, Palo Alto, CA). The polymers were dissolved in $\mathrm{D}_{2} \mathrm{O}$ or DMSO- $\mathrm{d}_{6}$. The molecular weights and molecular weight distributions of the synthesized copolymers $\mathrm{pHN}$ and C-pHN were determined by gel permeation chromatography (GPC) [39]. For the polymer C-pHNA and C-pHDA, the molecular weights and molecular weight distributions were determined by GPC using a Viscotek-GPC max (Viscotek, Oss, The Netherlands) light scattering $\left(\lambda=670 \mathrm{~nm}\right.$, right $\left(90^{\circ}\right)$ and low $\left(7^{\circ}\right)$ angle)/viscometric detection system, using a 
ultrahydrogel $2000,7.8 \times 300 \mathrm{~mm}$ column in series with a ultrahydrogel $6.0 \times 40 \mathrm{~mm}$ guard column (waters), $0.3 \mathrm{M}$ $\mathrm{NaAc}, \mathrm{pH} 4.4$, and $30 \%$ acetonitrile as eluent [40]. The flow rate was $0.6 \mathrm{~mL} / \mathrm{min}$ and the run time was $50 \mathrm{~min}$. PolyCAL ${ }^{\text {Tм }}$ PEO standard $\left(M_{\mathrm{n}}=24 \mathrm{kDa}, \mathrm{PDI}=1.01\right.$, Malvern) was used for calibration.

\section{Preparation and characterization of polymer/siRNA polyplexes}

\section{siRNA polyplex preparation}

siRNA duplexes for target genes were purchased from IDT (Coralville, IA, USA). The siRNA polyplexes preparation process consisted of 3 consecutive steps: complexation, pegylation, and lyophilization. Briefly, for complexation, four volumes of polymer and one volume of nucleic acid both dissolved in $10 \mathrm{mM} \mathrm{NaOAc}$ buffer, $\mathrm{pH}$ 5, at the desired N/P ratio, were mixed by vortexing with a final siRNA concentration of $50 \mu \mathrm{g} / \mathrm{mL}$. For pegylation, BCN-PEG (BCN-PEG$\mathrm{COOH}$ ) or BCN-PEG-cRGD as added to the polyplexes at the amount of PEG equivalent to $60 \mathrm{~mol} \%$ of an azide of the polymer used for preparing polyplexes and left to react for $2 \mathrm{~h}$ at room temperature. This ratio was selected based on our prior studies, in which we investigated the optimal postPEGylation ratio for RNA polyplexes [25, 34]. For freezedrying of the polyplexes, sucrose was added to the polyplex formulation to a final concentration of $5 \%$ before snapfreezing in liquid nitrogen. Frozen samples were freeze-dried overnight using an Alpha 1-2 LD plus freeze-dryer (Marin Christ, Osterode, Germany).

\section{Particle size and zeta-potential measurements}

Particle sizes of the polyplexes $(10 \mu \mathrm{g} / \mathrm{mL}$ siRNA concentration) were measured with dynamic light scattering (DLS) using an ALV CGS-3 system (Malvern Instruments, Malvern, U.K.) equipped with a JDS Uniphase $22 \mathrm{~mW} \mathrm{He}$ -Ne laser operating at $632.8 \mathrm{~nm}$, an optical fiber-based detector, and a digital LV/LSE-5003 correlator at $25^{\circ} \mathrm{C}$. The zetapotential of the polyplexes was measured at $25{ }^{\circ} \mathrm{C}$ using a Malvern Zetasizer Nano-Z (Malvern Instruments, Malvern, U.K.) in $10 \mathrm{mM}$ HEPES buffer. To detach PEG from CpHDA/siRNA polyplexes, the polyplexes were incubated with $10 \mathrm{mM}$ DTT at room temperature before measurement.

\section{Gel retardation assay}

Polyplexes prepared at different $\mathrm{N} / \mathrm{P}$ ratios were made by adding $5 \mu \mathrm{L}$ of polymer solution (concentrations varying between 14 and $2400 \mu \mathrm{g} / \mathrm{mL}$ in $10 \mathrm{mM}$ HEPES, $\mathrm{pH} 7.4$ ) to $5 \mu \mathrm{L}$ of siRNA solution $(40 \mu \mathrm{g} / \mathrm{mL}$ in $10 \mathrm{mM}$ HEPES, $\mathrm{pH} 7.4)$, followed by vortexing for $5 \mathrm{~s}$ and the dispersions were incubated for $30 \mathrm{~min}$ at room temperature. For release studies with heparin, the sample prepared at an N/P of $8(10 \mu \mathrm{L})$ was mixed with of $5 \mu \mathrm{L}$ heparin sodium salt (concentrations varying between 75 and $900 \mu \mathrm{g} / \mathrm{mL}$ ). Next, $1 \mu \mathrm{L}$ of sodium chloride $(1.54 \mathrm{M})$ was added to get a final salt concentration of $150 \mathrm{mM}$, and the samples were incubated for $10 \mathrm{~min}$ at room temperature [41]. Next, the gel was analyzed by a Gel Doc $\mathrm{XR}+$ system (BioRad Laboratories Inc., Hercules, CA) with Image Labsoftware.

\section{Transmission electron microscopy}

Transmission electron microscopy (TEM) was carried out on an FEI Tecnai T10 microscope from FEI Company (Eindhoven, The Netherland). Twenty microliters of polyplex dispersion of $50 \mu \mathrm{g} / \mathrm{mL}$ siRNA in $10 \mathrm{mM}$ HEPES, pH 7.4, were placed on a carbon-coated copper grid and left to dry. The samples were stained with $2 \%$ uranyl acetate. Scale bars were added with the help of ImageJ software.

\section{In vitro cytotoxicity and cell transfection study}

Human glioblastoma cells (line U87R-GFP; gift from Peter Forsyth, Moffitt Cancer Center, FL, USA) modified with luciferase were cultured in Dulbecco's Modified Eagles Medium (DMEM) F12 supplemented with $10 \%$ fetal bovine serum and $200 \mu \mathrm{g} / \mathrm{mL}$ G418 as previously described [42]. Cells were seeded at a density of 10,000 cells per well in 96well plate $24 \mathrm{~h}$ prior to polyplex addition. Cells were cultured in ( $10 \%$ HI FBS, ) before transfection, the medium was removed and replaced with opti-MEM or culture medium containing $10 \%$ FBS. siRNA polyplexes were then added to each well at a final siRNA concentration of 100 and $200 \mathrm{nM}$. lipofectamine 2000 (Invitrogen, Karlsruhe, Germany) (Lipo) was used as positive control (100 nM siRNA, Lipo/siRNA volume/weight ratio of 3/1), and formulations containing scrambled siRNA and PBS-treated cells were used as negative controls. After a 4-h incubation, the medium was replaced with culture medium containing $10 \%$ FBS.

To determine the cytotoxicity of the polyplexes the Alamar Blue cell viability assay (Invitrogen, Karlsruhe, Germany) was carried out. Forty-four hours following transfection, the cell medium was replaced with medium containing Alamar Blue $(50 \mathrm{nM})$ and incubated for $4 \mathrm{~h}$. Next, $80 \mu \mathrm{L}$ of medium from each well was then transferred into a flat-bottom 96-well plate. The relative cell metabolic activity was calculated by normalizing the absorbance at $570 \mathrm{~nm}$ (reference wavelength of $630 \mathrm{~nm}$ ) with the absorbance of PBS-treated cells.

Luciferase cellular expression was measured $48 \mathrm{~h}$ after transfection. Cells were washed with $100 \mu \mathrm{L}$ cold PBS and lysed with $100-\mu \mathrm{L}$ lysis buffer. Subsequently, 50- $\mu \mathrm{L}$ luciferase assay reagent (Promega) was added to $20-\mu \mathrm{L}$ cell lysate using a microinjector, and luminescence measured after $2 \mathrm{~s}$ 
using a white microplate, using an FLUOstar OPTIMA equipped with a luminescence light guide (BMG LabTech, Germany). To normalize for transfection efficiency, the GFP intensity was also measured. The relative luciferase activity in each well was obtained by dividing the luminescence intensity by the corresponding GFP fluorescent intensity. This activity was then normalized against the PBS-treated control samples [43].

\section{Cellular uptake of polyplexes studied by flow cytometry}

U87R-GFP-Luc2 cells were seeded into a 96-well plate $(30,000$ cells/well) and incubated with polyplexes prepared as described above using Cy5-labeled siRNA (final siRNA concentration was $100 \mathrm{nM}, \mathrm{N} / \mathrm{P}$ ratio of 8) for $4 \mathrm{~h}$ at $37{ }^{\circ} \mathrm{C}$ in medium with serum incomplete sentence). For the cRGD competition study, the cells were first treated for $1 \mathrm{~h}$ with $200 \mathrm{nM}$ cRGD before addition of polyplexes. Cells were then washed twice with ice-cold PBS. To quench the fluorescence of polyplexes associated with the cell membrane, the cells were incubated with $0.4 \%$ trypan blue-containing PBS for 5 min and washed with PBS [44]. Following trypsinization cells were collected and suspended in PBS. Cellular uptake of siRNA polyplexes was then examined through flow cytometry with help of Canto II (BD, USA).

\section{Confocal laser scanning microscopy studies}

U87R-GFP-Luc2 cells were seeded into 96-well $\mu$ Clear ${ }^{\circledR}$ black plates $(20,000$ cells/ well) and incubated for $24 \mathrm{~h}$ in full medium. Polyplexes with Cy5-labeled siRNA (final siRNA concentration was $100 \mathrm{nM}, \mathrm{N} / \mathrm{P}$ ratio of 8) were added and the cells were subsequently incubated for another $4 \mathrm{~h}$ at $37^{\circ} \mathrm{C}$. For the cRGD competition study, the cells were first incubated with $200 \mathrm{nM}$ cRGD for $1 \mathrm{~h}$ before adding the polyplexes. Prior to imaging, the medium was replaced with fresh full medium containing Hoechst33342 and Lysotracker Red (Molecular Probes, Oregon, USA) for staining the nuclei and lysosomes (incubation at $37{ }^{\circ} \mathrm{C}$ for $20 \mathrm{~min}$ ). After washing with PBS, CLSM images were recorded using Yokogawa CV7000S imager (Yokogawa group, Tokyo, Japan) equipped with a $60 \times$ water immersion objective at an excitation wavelength of 405, 488, 561, and $646 \mathrm{~nm}$ for Hoechst33342, GFP, Lysotracker Red, and siRNA-Cy5, respectively.

\section{Statistical analysis}

$p$ values were determined by Student's test with two-tailed distribution performed with the software GraphPad Prism 5 (GraphPad Software Inc. La Jolla, California). $p$ values $<0.05$ were considered as statistically significant.

\section{Results and discussion}

\section{Synthesis and characterization of random copolymers}

A random copolymer poly (HPMA-r-NAS) (pHN) was synthesized by RAFT polymerization, as shown in Fig. 1b, through a procedure, described previously [37]. Due to the significantly different reactivity ratios of HPMA $\left(\mathrm{r}_{\mathrm{HPMA}}=\right.$ $0.29)$ and NAS $\left(r_{\text {NAS }}=1.99\right)$, RAFT copolymerization of those two monomers could lead to the compositional drift during polymerization. Interestingly, Moraes et al. found that RAFT polymerization of HPMA and NAS in DMF at a specific feed ratio of $30 \mathrm{~mol} \%$ NAS resulted in a minimal compositional drift [37]. Therefore, $\mathrm{pHN}$ was synthesized using this feed ratio at a total monomer concentration of $1 \mathrm{M}$ (Fig. 1b). The monomer conversions were determined using the ratio of the vinyl peak of the monomers $(5.61 \mathrm{ppm}$ for HPMA and $6.31 \mathrm{ppm}$ for NAS) to the methylene peak (5.07 ppm) of internal standard 1,3,5-trioxane. ${ }^{1} \mathrm{H}$ NMR analysis showed that after a reaction time of $9 \mathrm{~h}$, the conversions of HPMA and NAS were 64 and 57\%, respectively. After purification, the copolymer composition was also determined by ${ }^{1} \mathrm{H}$ NMR spectroscopy. The molar ratio of HPMA/NAS in the copolymer was calculated by comparing the integrals at $3.65 \mathrm{ppm}$ (methine protons of HPMA) and at $2.79 \mathrm{ppm}$ (methylene protons of NAS), with a result of $28 \%$ mol of NAS in the copolymer (Fig. 2b). This is in excellent agreement with the value of NAS composition (29\%) as determined by the conversion of the monomers, which suggests the NAS groups were not hydrolyzed during the polymerization and precipitation processes. GPC analysis showed that the obtained $\mathrm{pHN}$ had a number average molecular weight of $15,800 \mathrm{~g} / \mathrm{mol}$, with a relatively low polydispersity index (PDI) of 1.43 (Fig. 1c; Table 1), which is similar to the results from literature (PDI = 1.37) [37]. The deviation of the molecular weight from theoretical molecular weight $\left(M_{\mathrm{n}}=9800 \mathrm{~g} / \mathrm{mol}\right)$ calculated on the basis of the monomer conversion is attributed to the fact that calibration was done with PEG standards.

The chain transfer agent (CTA) used for the polymerization typically yields a dithioester or trithioester group at the $\omega$-end of the polymer chain, which is available for further postpolymerization functionalization $[45,46]$. A radical crosscoupling reaction [38] between the trithiocabonate chain end and a cholesterol modified azo-initiator was used to introduce a cholesterol moiety at the $\omega$-end of pHN (Fig. 1b). The cholesterol modified initiator was synthesized using DCCmediated esterification of the hydroxyl group of cholesterol and carboxylic acid of V501, yielding $\mathrm{C}-\mathrm{V}_{501}-\mathrm{C}$ in $45 \%$ yield (Fig. 1a). ${ }^{1} \mathrm{H}$ NMR spectrum (Fig. S1a) shows the disappearance of the signal at $3.51 \mathrm{ppm}$ (assigned to the methine protons of cholesterol) and appearance of a new signal at $4.60 \mathrm{ppm}$ (assigned to the methine protons of $\mathrm{C}-\mathrm{V}_{501}-\mathrm{C}$ ) suggests the formation of an ester bond between cholesterol and 
Table 1 Characteristics of synthesized random copolymers

\begin{tabular}{|c|c|c|c|c|c|c|c|}
\hline Polymers & Abbreviation & $\begin{array}{l}\text { HPMA }(\% \\
\text { mol })^{\mathrm{a}}\end{array}$ & $\begin{array}{l}\text { NAS }(\% \\
\text { mol })\end{array}$ & $\begin{array}{l}\text { HPMA-DMAE } \\
(\% \mathrm{~mol})\end{array}$ & $\begin{array}{l}\text { ADAE } \\
(\% \mathrm{~mol})\end{array}$ & $\begin{array}{l}M_{\mathrm{n}} \\
(\mathrm{g} / \mathrm{mol})\end{array}$ & $\begin{array}{l}M_{\mathrm{w}} / \\
M_{\mathrm{n}}\end{array}$ \\
\hline P(HPMA-r-NAS) & $\mathrm{pHN}$ & $72(64 \%)^{\mathrm{b}}$ & $28(60 \%)^{\mathrm{b}}$ & 0 & 0 & $15,800^{\mathrm{c}}$ & 1.43 \\
\hline P(HPMA-r-NAS)-cholesteryl & C-pHN & 73 & 27 & 0 & 0 & $17,700^{\mathrm{c}}$ & 1.40 \\
\hline P(HPMA-r-ADAE)-cholesteryl & C-pHNA & 80 & 0 & 0 & $20(88 \%)^{\mathrm{b}}$ & $24,700^{\mathrm{d}}$ & 1.20 \\
\hline P(HPMA-DMAE-r-ADAE)-cholesteryl & C-pHDA & 19 & 0 & $61(75 \%)^{b}$ & 20 & $34,100^{\mathrm{d}}$ & 1.30 \\
\hline $\begin{array}{l}\text { Control polymer } \\
\text { P(HPMA-DMAE-r-ADAE) }\end{array}$ & pHDA & 18 & 0 & 59 & 23 & $25,600^{d}$ & 1.33 \\
\hline
\end{tabular}

${ }^{\text {a }}$ Copolymer composition as determined by ${ }^{1} \mathrm{H}$ NMR analysis

${ }^{\mathrm{b}}$ Conversion of each step (percentage) calculated from ${ }^{1} \mathrm{H}$ NMR

${ }^{\mathrm{c}}$ Determined by GPC

${ }^{\mathrm{d}} \mathrm{GPC}$ viscotek analysis

V501. The ester bond formation was further verified by the ATR-FTIR with its absorbance at a wavenumber of $1743 \mathrm{~cm}^{-1}$ (Fig. S1b). Radical cross-coupling of $\mathrm{pHN}$ and $\mathrm{C}-\mathrm{V}_{501}-\mathrm{C}$ was performed at $70{ }^{\circ} \mathrm{C}$ in DMF for $4 \mathrm{~h}$ (Fig. 1b). ${ }^{1} \mathrm{H}$ NMR analysis of the obtained polymer confirmed incorporation of the cholesterol moiety as evident by the appearance of peaks at $0.61 \mathrm{ppm}$ (methyl protons of cholesterol) and $5.30 \mathrm{ppm}$ (methylene protons of cholesterol) in the NMR spectrum (Fig. 2a). NMR analysis further showed that around $60 \%$ of pHN chains had a cholesterol terminus. The GPC chromatogram of $\mathrm{pHN}$ and C-pHN showed that there was no significant change in the molecular weight distribution (Fig. 1c) and polydispersity index (Table 1), and the decrease of the UV absorbance (90\%) (Fig. S2) at $309 \mathrm{~nm}$ (thiocarbonylthio chromophore) [45] demonstrates again successful cross-coupling of cholesterol to the polymer. The resulting polymer C-pHN contained $27 \mathrm{~mol} \%$ of NAS (calculated from NMR) demonstrated that these reactive esters were not hydrolyzed, due to possible presences of traces of water, during cholesterol modification and are therefore available for further post-polymerization modification.

The cholesteryl poly(HPMA-r-NAS) (C-pHN) copolymer was subsequently modified with 2-((2-azidoethyl) disulfanyl) ethan-1-amine hydrochloride (ADAE) to introduce azide groups which can be exploited for conjugation of compounds with bicyclo[6.1.0]nonyne (BCN) groups (using copper-free click chemistry (Scheme 1). [47] ADAE was synthesized via the conversion of one of the cystamine amines into azide, according to a previous study (Scheme S1) [36]. ${ }^{1} \mathrm{H}$ NMR analysis and the absorbance at a wavenumber of $2300 \mathrm{~cm}^{-1}$ in ATR-IR spectrum showed the success of azide formation (Fig. S3). C-pHN was first reacted with ADAE, followed by an excess of 1-amino-propan-2-ol to quench remaining unreacted NAS units (Scheme 1a). ${ }^{1} \mathrm{H}$ NMR analysis of the obtained azide polymer (C-pHNA) (the decreased integral of $2.79 \mathrm{ppm}$ ) confirmed the reaction between NAS and ADAE (Fig. S4). The C-pHNA containing $20 \mathrm{~mol} \%$ of ADAE meaning that the conjugation efficiency was $88 \%$ (Table 1). The C-pHNA polymer was further modified with 2-(dimethylamino) ethyl-imidazole-1-carboxylate (DMAECI), coupled via a carbonate ester bond, to get the final polymer C-pHDA (Scheme 1b). As shown in Fig. 3, the decrease in intensity of the methine proton of the HPMA peak at $3.7 \mathrm{ppm}$ and the appearance of a peak at $2.3 \mathrm{ppm}$ (the methyl groups of DMAE) demonstrates that $75 \%$ of the $\mathrm{OH}$ groups of HPMA had reacted with DMAE groups. SEC analysis of the copolymer before and after DMAE modification showed a monomodal distribution with a relatively narrow distribution (PDI < 1.4) (Fig. S5).

\section{Formation of C-pHDA polyplexes and in vitro siRNA delivery}

The effect of introducing cholesterol moieties in the polymer on the formation of siRNA polyplexes and gene delivery properties were studied. Agarose gel electrophoresis and dynamic light scattering techniques were employed to study the interaction of polymers with siRNA. A representative gel electrophoretic pattern is shown in Fig. 4a. siRNA was mixed with a polymer with (C-pHDA) or without (pHDA) cholesterol moiety (Table 1), at varying molar ratio of amine in the polymer to phosphate in siRNA (N/P ratio) from 0.5 to 12 . Complete siRNA complexation (absence of free siRNA bands in the gel) for pHDA was achieved at N/P ratio of 4 and above, whereas for $\mathrm{C}-\mathrm{pHDA}$ this was achieved at N/P 3. These data indicate that there was no hindering of the complexation of siRNA following the introduction of cholesterol on the $\omega$-end of pHDA. This is consistent with results previously obtained, in which cholesterol was introduced into PAsp(DET)-PEG copolymer [33, 48]. Table S1 reports the size and zeta potential of C-pHDA polyplexes prepared at varying N/P ratios. At $\mathrm{N} / \mathrm{P}$ ratio 2 , the average size of polyplexes was largest $(319 \mathrm{~nm})$ and with a near-neutral charge $(5 \mathrm{mV})$, which implies it is close to the charge neutralization point between $\mathrm{C}$ - 


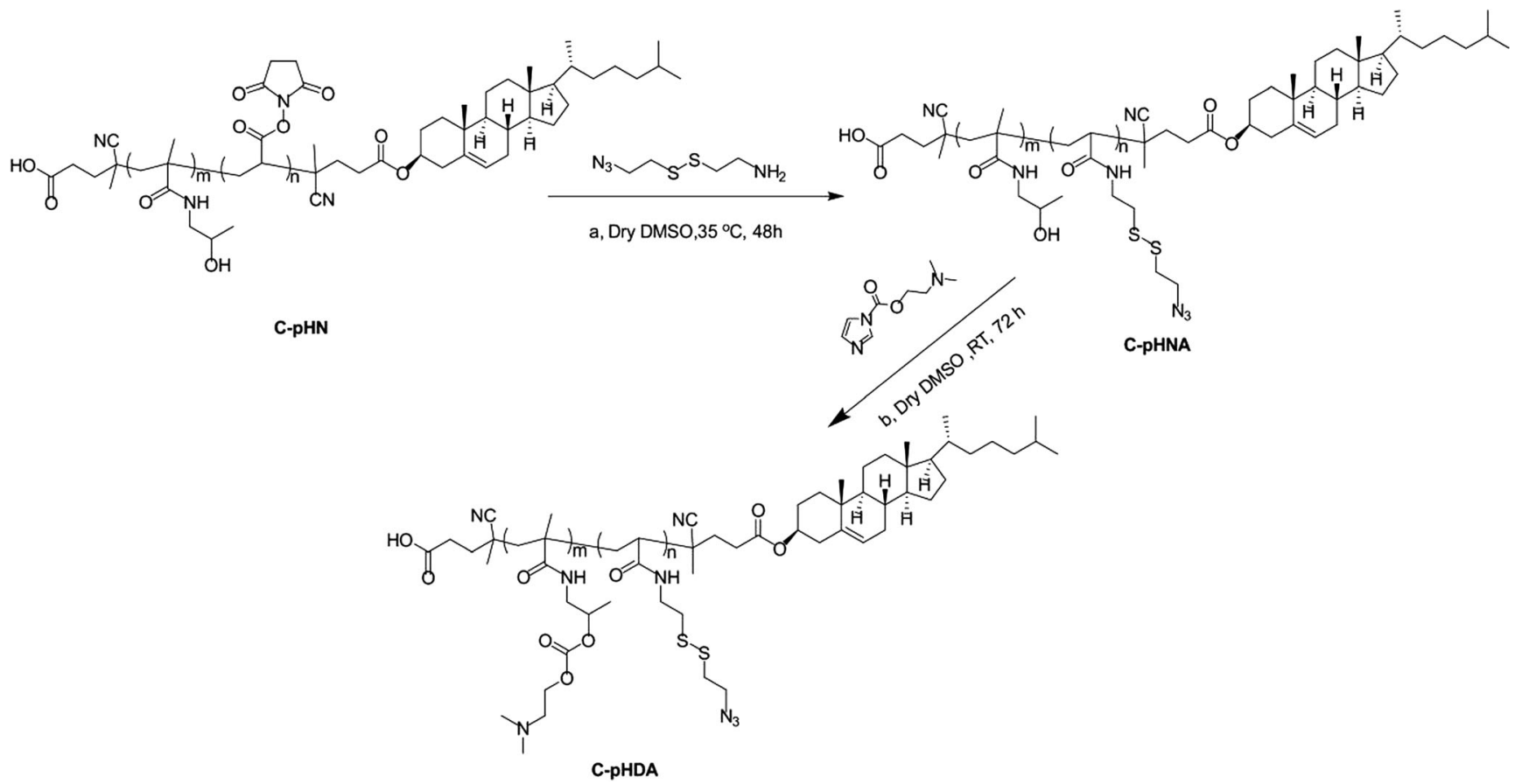

Scheme 1 Post-polymerization modification of cholesteryl p(HPMA-r-NAS)

pHDA and siRNA, consistent with the gel retardation results. The particle size and scattering light intensity (SLI) decreased with increasing N/P ratios in the range of 2-12, together with the increased polydispersity (PDI) of the polyplexes. Thus, an $\mathrm{N} / \mathrm{P}$ ratio of 8 was selected for further evaluation, at which $\mathrm{C}$ pHDA form particles of $37 \mathrm{~nm}$ and with an acceptable PDI $(<$ 0.35). It should be noted that the PDI of C-pHDA polyplexes
(0.34) is higher than that of pHDA polyplexes $(0.24)$ at $\mathrm{N} / \mathrm{P}$ ratio of 8 , which is probably due to the presence of cholesterol moieties in the C-pHDA polyplexes that may cause some aggregation. The effect of cholesterol on polyplex stability at increasing ionic strength was also evaluated (Fig. 4b). After incubation with $150 \mathrm{mM} \mathrm{NaCl}$ (physiological ionic strength) in $10 \mathrm{mM}$ HEPES buffer for half an hour, the size of pHDA/
Fig. $3{ }^{1} \mathrm{H}$ NMR $\left(\mathrm{D}_{2} \mathrm{O}\right)$ spectrum of C-pHDA

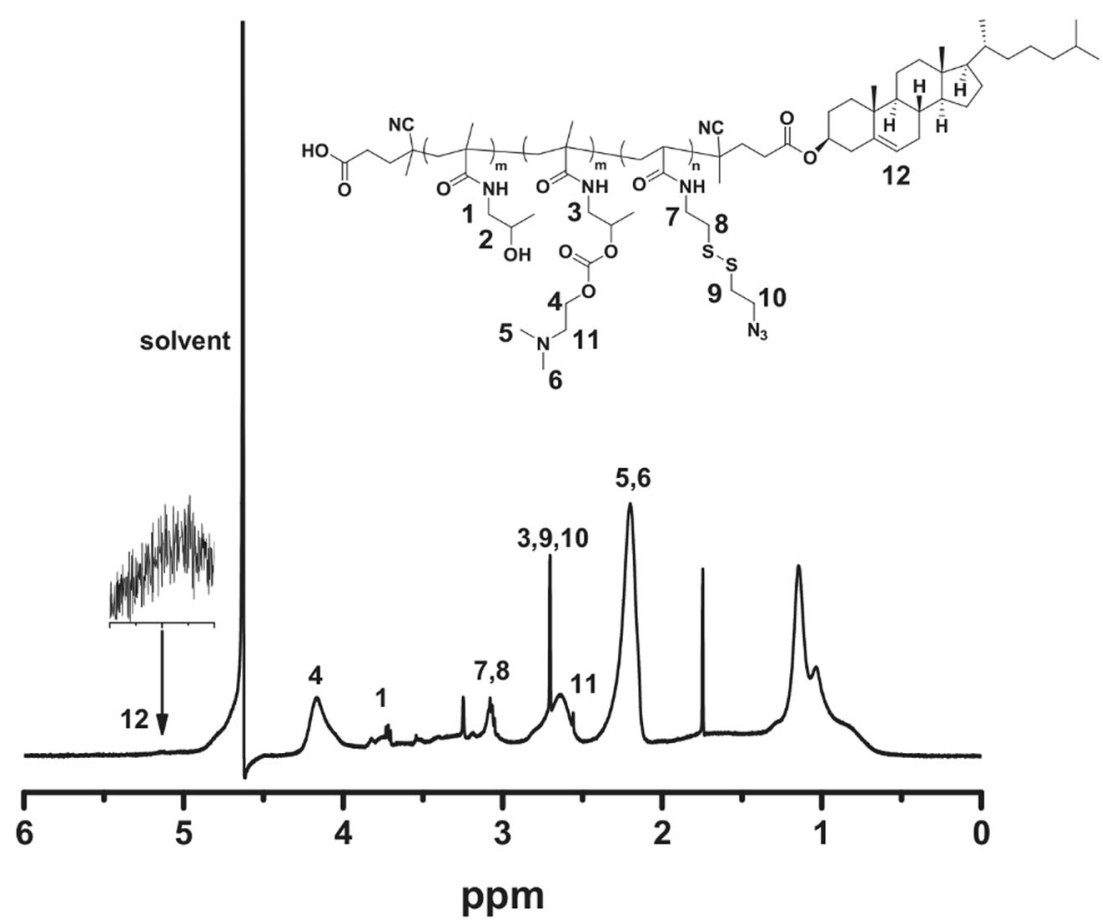


Fig. 4 a Agarose gel retardation assay of the polymer/siRNA polyplexes at different N/P ratios. To study heparin-induced polyplex destabilization, siRNA polyplexes were incubated with heparin $(200 \mu \mathrm{g} / \mathrm{mL})$ for $10 \mathrm{~min}$ in $10 \mathrm{mM}$ HEPES buffer (pH 7.4, containing $150 \mathrm{mM} \mathrm{NaCl}$ ); b particle size of siRNA polyplexes at concentration of $10 \mu \mathrm{g} / \mathrm{ml}, \mathrm{N} / \mathrm{P}$ molar ratio of 8 , before and after $150 \mathrm{mM} \mathrm{NaCl}$ for $0.5 \mathrm{~h}$; c transfection efficiency and $\mathbf{d}$ cytotoxicity of siRNA polyplexes at N/P ratio of 8 with a final siRNA concentration of $100 \mathrm{nM}$. $* * * * p<0.0001, * * p<0.01, \mathrm{~ns}$ no significantly difference. Blank, untreated cells; Lipo, lipofectamine 2000; NC, negative control siRNA. Representative results from one of three experiments are shown. All values are given as the mean $\pm \mathrm{SD}(n=3)$ a)
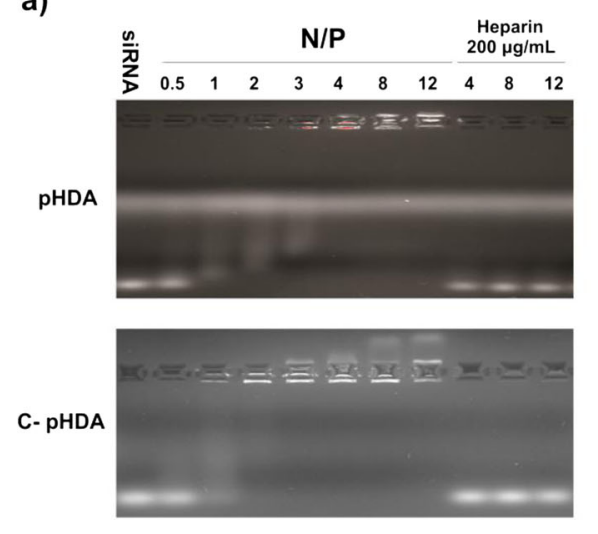

c)

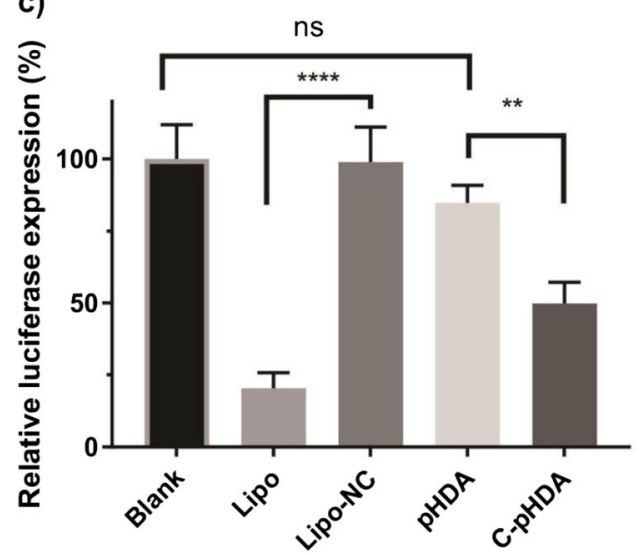

b)

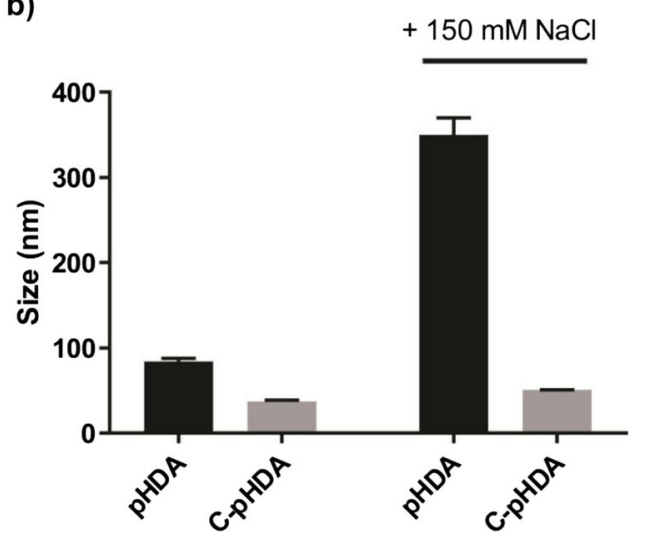

d)

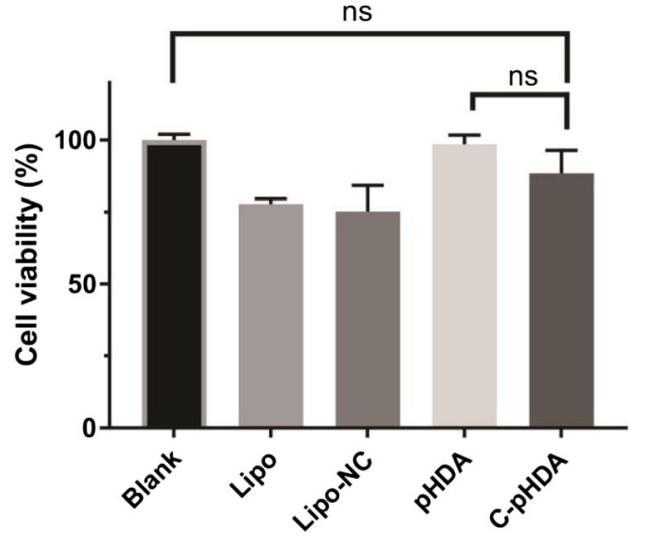

siRNA polyplexes increased from 90 to $350 \mathrm{~nm}$, which is normal for cationic polyplexes without PEG shielding [49]. In contrast, the size of C-pHDA/siRNA polyplexes only slightly increased from 37 to $60 \mathrm{~nm}$, demonstrating that the hydrophobic interaction between the cholesterol moieties could significantly enhanced the stability of the C-pHDA siRNA polyplexes.

The effect of the presence of cholesterol in the polyplexes on siRNA transfection efficiency was evaluated in the invasive U87R-GFP-Luc2 GBM cell line, which co-expresses green fluorescence protein (GFP) and luciferase (Luc) from a bicistronic transcript. To exclude the influence of serum, the polyplexes were incubated with the cells OPTI-MEM medium without serum, which favors stability of unshielded, cationic polyplexes, and lipoplexes made with commercial agent lipofectamine 2000 (Lipo). At an N/P 8, C-pHDA polyplexes containing anti-luciferase siRNA potently silenced around $50 \%$ of the expression of luciferase, which was significantly higher than observed for the polyplexes based on pHDA ( $10 \%$ silencing) (Fig. 4c). The improved gene-silencing efficacy of c-PHDA polyplexes compared to pHDA polyplexes is likely caused by the smaller size ( $37 \mathrm{vs} 90 \mathrm{~nm}$ ) and higher surface charge ( $25 \mathrm{vs} 16 \mathrm{mV}$ ) of the polyplexes, as the size and zeta potential of polyplexes strongly influence the transfection efficiency [50]. Moreover, polyplexes prepared by pHDA and
C-pHDA showed minimal cytotoxicity to U87R cells (Fig. 4d). These data again demonstrate that p(HPMADMAE) has an excellent cytocompatibility, in agreement with a previous study using different cell lines [51]. In conclusion, the introduction of cholesterol into the polymer enhanced the stability of formed siRNA polyplexes and leads to smaller particle size and higher gene-silencing efficacy.

\section{Effect of post-PEGylation of C-pHDA polyplexes with PEG-CRGD on cellular uptake and transfection efficiency}

To shield the positive surface charges of C-pHDA-siRNA polyplexes, post-PEGylation via copper-free click chemistry was applied. Cyclic RGD (cRGD) was coupled to the distal end of $\mathrm{PEG}$ to enable binding to integrin receptors overexpressed on angiogenic blood vessels and tumors, including human GBM cells [52-54]. BCN-PEG-cRGD was synthesized according to scheme S2 and characterized by ${ }^{1} \mathrm{H}$ NMR spectroscopy (Fig. S6 and S7) and SEC analysis (Fig. S8). PostPEGylation was carried out by adding BCN-PEG (BCN-PEG$\mathrm{COOH}$ ) or BCN-PEG-cRGD to preformed C-pHDA polyplexes, followed by freeze-drying which results in an acceleration of the click reaction $[25,55]$. For lyophilization, $5 \%$ sucrose was added as lyoprotectant. As shown in Table 1, after 
Table 2 Size and zeta potential of siRNA/C-pHDA polyplexes

\begin{tabular}{llcc}
\hline Polyplexes & Size $(\mathrm{nm})$ & Zeta potential $(\mathrm{mV})$ & PDI \\
\hline No PEGylation & $37 \pm 1$ & $25.0 \pm 2.1$ & 0.34 \\
PEG & $56 \pm 2$ & $9.4 \pm 1.2$ & 0.36 \\
PEG-cRGD & $50 \pm 3$ & $8.7 \pm 0.2$ & 0.35 \\
\hline
\end{tabular}

Prepared at $\mathrm{N} / P=8$ and after lyophilization resuspended at a siRNA concentration of $10 \mu \mathrm{g} / \mathrm{mL}$ in $10 \mathrm{mM}$ HEPES buffer, $\mathrm{pH}$ 7.4. Data are presented as mean $\pm \mathrm{SD}(n=3)$

PEGylation, the size of C-pHDA polyplexes increased from 37 to $56 \mathrm{~nm}$, with a decrease of surface charge ( 25 to $9.4 \mathrm{mV}$ ). It is important to note that the PEGylation process did not lead to detectable siRNA release, as characterized by gel electrophoresis before and after lyophilization (Fig. S9). Therefore, the decrease of the surface charge is due to its shielding by the grafted PEG chains. No changes in PDI were detected after lyophilization, demonstrating that the freeze-drying procedure did not cause aggregation of the particles. The PEG-cRGD post-modified siRNA polyplexes resulted in similar size $(50 \mathrm{~nm})$, as confirmed by TEM (Fig. S10). Further, the observation that the PDI did not change indicates that the possible presence of BCN-PEG-BCN during the synthesis procedure of BCN-PEGcRGD did not cause significant inter-polyplex cross-linking, likely because the formulations were prepared at relatively low particle concentration (siRNA was $50 \mu \mathrm{g} / \mathrm{mL}$ ). In addition, the zeta potential of polyplexes was measured to confirm detachment of PEG following incubation of the polyplexes with DTT; the zeta potential increased from 9.4 to around $20 \mathrm{mV}$, close to the zeta potential of non-PEGylated polyplexes $(25 \mathrm{mV})$ (Fig. S11). This demonstrates that a significant fraction of PEG was detached (Table 2).

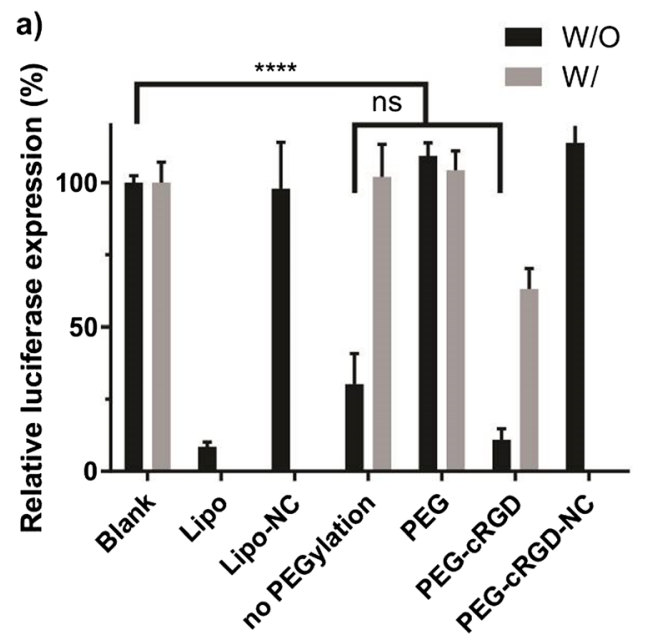

Fig. 5 Luciferase gene expression (a) and cytotoxicity (b) of different functionalized C-pHDA/siRNA polyplexes following transfection into U87R-GFP-Luc2 in the absence or presence of serum. Cells transfected with lipofectamine (Lipo) in the absence of serum were utilized as a
To verify the siRNA biological delivery effects of PEG (cRGD) post-modification on c-pHDA polyplexes, in vitro transfection activity and cytotoxicity were investigated. U87R-GFP-Luc2 cells were transfected with anti-luc siRNA formulations in the presence and absence of serum. U87RGFP-Luc2 was chosen as a target cell line due to their overexpression of integrins on their cellular surface [56] and thus appropriate for assessing the cRGD targeting effect on cellular uptake and transfection. As shown in Fig. 5a, when the cells were incubated with formulations in the absence of serum, non-PEGylated and PEG-cRGD-modified polyplexes showed high gene knock-down efficacy ( $>70 \%)$, which is comparable to the positive control lipofectamine. PEG-cRGD polyplexes prepared with scrambled siRNA did not silence luciferase expression. Importantly, PEGylated polyplexes without cRGD-targeting ligand showed no gene silencing, presumably due to limited cellular uptake. In the presence of serum, only PEG-cRGD polyplexes showed significant luciferase silencing (40\%). The low gene-silencing activity of C-pHDA siRNA polyplexes in the presence of serum is most likely explained by a substantial decrease in cellular uptake (Fig. S12), presumably due to the interaction of serum proteins with cationic charged polyplexes that can lead to the premature release of siRNA. Alternatively, the absorbance of serum proteins can change the surface charge of particles leading to a reduced interaction with cell membranes. The results presented in Fig. S12c demonstrate that more siRNA was colocalized with late endosome/lysosome when transfected in the presence of serum (in comparison with transfection without serum) indicating that serum proteins could possibly change the endocytosis pathway of C-pHDA siRNA polyplexes. Again, the Alarmar Blue assay showed limited cytotoxicity for the formulations tested (Fig. 5b).

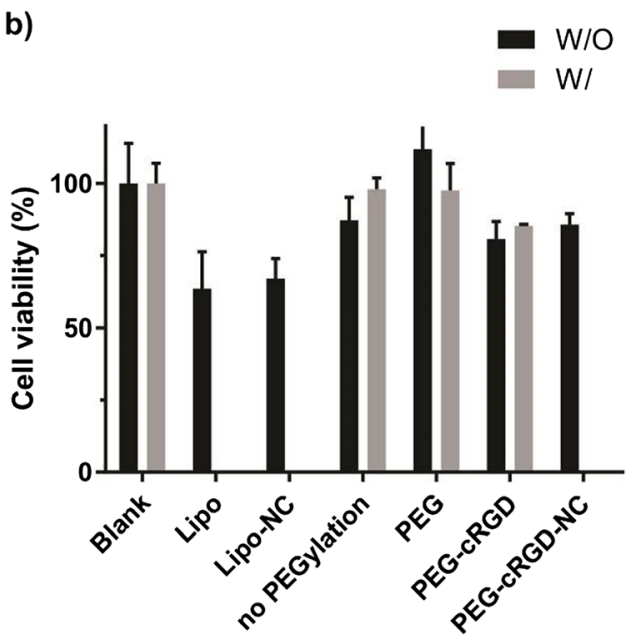

control. Final siRNA concentration was 200 nM. Blank, untreated cells; $\mathrm{NC}$, negative control scramble siRNA; W/O, in the absence of serum; W/, in the presence of serum. Representative results from one of the three experiments are shown. Values are given as the mean $\pm \operatorname{SD}(n=3)$ 
Fig. 6 Cellular uptake of Cy5labeled C-pHDA/siRNA polyplexes $(\mathrm{N} / P=8)$ by $\mathrm{U} 87 \mathrm{R}$ GFP-Luc2 cells in the presence of serum after 4-h incubation at $37^{\circ} \mathrm{C}$ measured by flow cytometry (a) and confocal microscopy (b); all images are overlays of the fluorescent signals from Cy5siRNA (red), lysosome red (green), GFP (cyan), and cell nucleus Hoechst33342 (blue). Scale bar indicates $10 \mu \mathrm{m}$. c Quantification of Cy5-labeled siRNA co-localization with LysoTracker Red in the U87RGFP-Luc2 cells analyzed using ImageJ software

a)

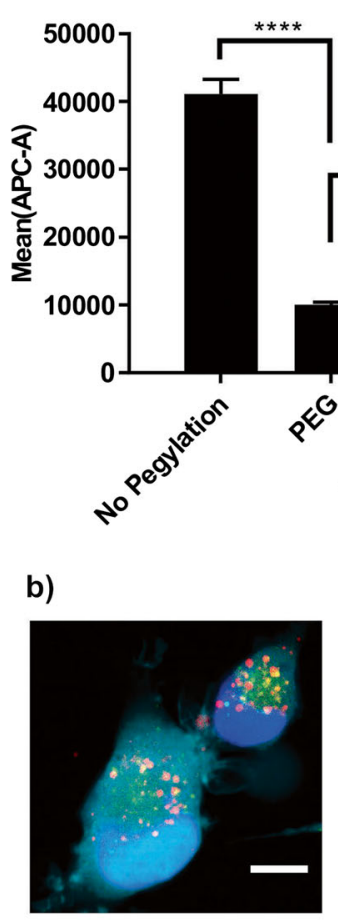

No PEGylation
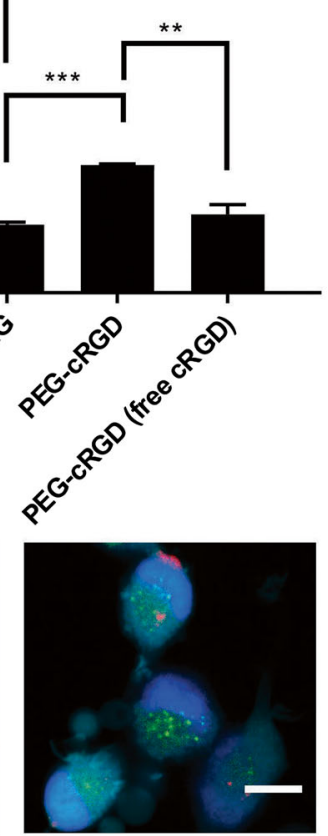

PEG
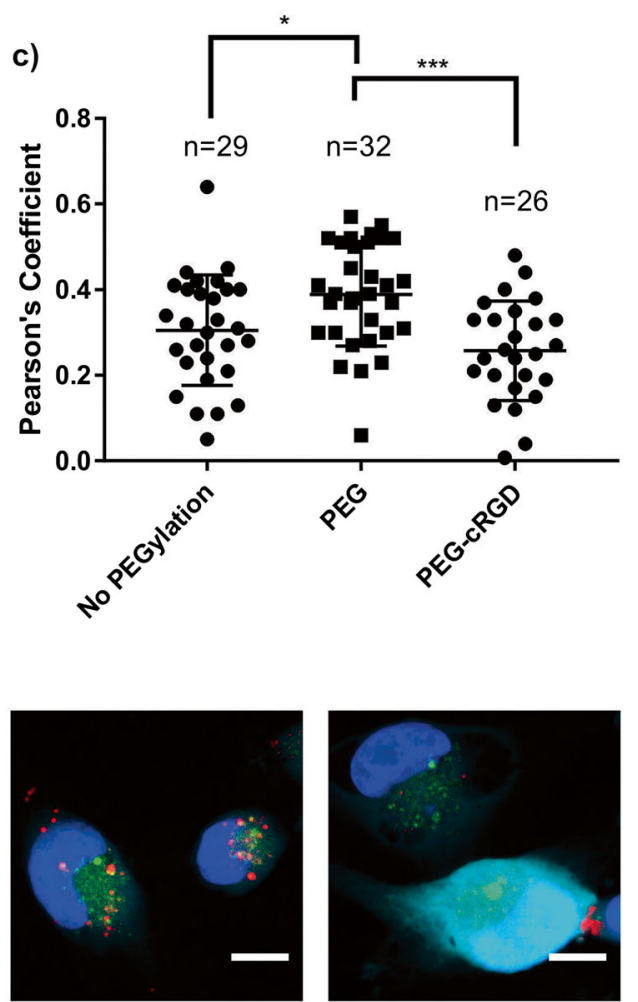

PEG-cRGD

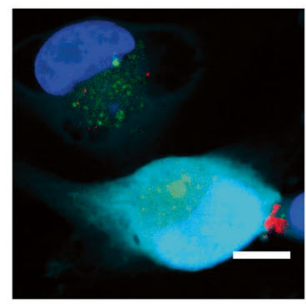

PEG-cRGD (Free cRGD)
To determine whether differences in gene-silencing efficiencies of various polyplex formulations could be attributed to differences in cellular uptake, both flow cytometry (Fig. 6a) and confocal fluorescence microscopy studies (Fig. 6b and Fig. S13) were performed in the presence of serum. As shown in Fig. 6a, after PEGylation, the level of cellular uptake of fluorescently labeled siRNA was substantially decreased compared to non-PEGylated formulations, potentially explaining why PEGylated formulations without cRGD decoration were not successful in silencing luciferase expression (Fig. 5a). The uptake efficiency of siRNA was augmented two-fold when PEG-cRGD was present, indicating that the cRGD ligand does indeed increase cellular uptake of the polyplexes via integrin receptor-mediated endocytosis. Cellular uptake was reduced by pre-incubation of the cells with free cRGD, showing that binding and subsequent uptake is indeed cRGDmediated (Fig. 6a and b). In addition to improving cell uptake, the cRGD peptide may also affect the intracellular process of ligand-equipped polyplexes. Several publications have shown that that RGD motif can destabilize the membrane at low $\mathrm{pH}$ and trigger the enhanced endosomal release of adenovirus [57, 58]. To investigate the subcellular distribution of fluorescentlabeled siRNA, lysosome compartments were stained with LysoTracker Red, which is a specific marker for acidic organelles. With the co-localization analysis of siRNA and lysosome by software ImageJ, PEG-cRGD-modified polyplexes showed a significantly reduced co-localization with lysosomal compartments, compared with PEG-modified polyplexes (Fig. 6c). This implies that the cRGD-decorated polyplexes may facilitate the siRNA transport to the cytosol, as also shown in previous studies [7, 59] and might explain the highly increased siRNA knock-down efficiency of cRGD ligandequipped polyplexes observed (Fig. 5a).

\section{Conclusion}

We have described the synthesis, preparation, characterization, and in vitro assessment of a novel cRGD-targeting and cholesterol stabilized polyplex system for siRNA delivery in GBM. Cholesterol moieties were introduced to the $\omega$-end of polymer chain after RAFT polymerization, followed by conjugating with cationic charge amines and azide functional groups. The resultant polymer was able to condense siRNA to form small nanoparticles size around $40 \mathrm{~nm}$ with improved stability. Relative to pDHA polyplexes alone, these stable and targeted c-pHDA polyplexes demonstrate improved cellular uptake in targeted U87R-GFP-Luc2 cells and mediate an efficient gene-silencing effect with a low cytotoxicity profile. These data support further investigation of these polyplexes for in vivo delivery using clinically relevant GBM models. 
Funding information Bo Lou was funded by the China Scholarship Council (CSC). This work was supported in part by a Science Foundation Ireland Technology Innovation Award (15/TIDA/2963). ATB is further supported by the "GLIOTRAIN" (http://www.gliotrain. eu) award, a Horizon 2020 Research and Innovation program funded under the Marie Skłodowska-Curie ETN initiative (Grant Agreement \#766069).

Open Access This article is distributed under the terms of the Creative Commons Attribution 4.0 International License (http:// creativecommons.org/licenses/by/4.0/), which permits unrestricted use, distribution, and reproduction in any medium, provided you give appropriate credit to the original author(s) and the source, provide a link to the Creative Commons license, and indicate if changes were made.

\section{References}

1. Kohler BA, Ward E, McCarthy BJ, Schymura MJ, Ries LAG, Eheman C, et al. Annual report to the nation on the status of cancer, 1975-2007, featuring tumors of the brain and other nervous system. JNCI J Natl Cancer Inst. 2011;103:714-36. https://doi.org/10.1093/ jnci/djr077.

2. Stupp R, Mason W, van den Bent MJ, Weller M, Fisher BM, Taphoorn MJB, et al. Radiotherapy plus concomitant $\mid$ nand adjuvant temozolomide for glioblastoma. N Engl J Med. 2005;352: 987-96. https://doi.org/10.1056/NEJMoa043330.

3. Vader P, Van Der Meel R, Symons MH, Fens MHAM, Pieters E, Wilschut KJ, et al. Examining the role of Rac1 in tumor angiogenesis and growth: a clinically relevant RNAi-mediated approach. Angiogenesis. 2011;14:457-66. https://doi.org/10.1007/s10456011-9229-x.

4. Lozada-Delgado EL, Grafals-Ruiz N, Vivas-Mejía PE. RNA interference for glioblastoma therapy: innovation ladder from the bench to clinical trials. Life Sci. 2017;188:26-36. https://doi.org/10.1016/ j.lfs.2017.08.027.

5. Hou J, Diao Y, Li W, Yang Z, Zhang L, Chen Z, et al. RGD peptide conjugation results in enhanced antitumor activity of PD0325901 against glioblastoma by both tumor-targeting delivery and combination therapy. Int J Pharm. 2016;505:329-40. https://doi.org/10. 1016/j.ijpharm.2016.04.017.

6. Liu S, Huang W, Jin MJ, Fan B, Xia GM, Gao ZG. Inhibition of murine breast cancer growth and metastasis by survivin-targeted siRNA using disulfide cross-linked linear PEI. Eur J Pharm Sci. 2016;82:171-82. https://doi.org/10.1016/j.ejps.2015.11.009.

7. Oe Y, Christie RJ, Naito M, Low SA, Fukushima S, Toh K, et al. Actively-targeted polyion complex micelles stabilized by cholester$\mathrm{ol}$ and disulfide cross-linking for systemic delivery of siRNA to solid tumors. Biomaterials. 2014;35:7887-95. https://doi.org/10. 1016/j.biomaterials.2014.05.041.

8. Lin C, Engbersen JFJ. Effect of chemical functionalities in poly(amido amine)s for non-viral gene transfection. J Control Release. 2008;132:267-72. https://doi.org/10.1016/j.jconrel.2008. 06.022 .

9. Novo L, van Gaal EVB, Mastrobattista E, van Nostrum CF, Hennink WE. Decationized crosslinked polyplexes for redoxtriggered gene delivery. J Control Release. 2013;169:246-56. https://doi.org/10.1016/j.jconrel.2013.03.035.

10. Wang L, Kristensen J, Ruffner DE. Delivery of antisense oligonucleotides using HPMA polymer: synthesis of a thiol polymer and its conjugation to water-soluble molecules. Bioconjug Chem. 1998;9: 749-57. https://doi.org/10.1021/bc980034k.

11. York AW, Huang F, McCormick CL. Rational design of targeted cancer therapeutics through the multiconjugation of folate and cleavable siRNA to RAFT-synthesized (HPMA-s-APMA) copolymers. Biomacromolecules. 2010;11:505-14. https://doi.org/10. 1021/bm901249n.

12. Kopecek J, Kopecková P. HPMA copolymers: origins, early developments, present, and future. Adv Drug Deliv Rev. 2010;62:12249. https://doi.org/10.1016/j.addr.2009.10.004.

13. Lammers T, Ulbrich K. HPMA copolymers: 30 years of advances. Adv Drug Deliv Rev. 2010;62:119-21. https://doi.org/10.1016/j. addr.2009.12.004.

14. Funhoff AM, Van Nostrum CF, Janssen APCA, Fens MHAM, Crommelin DJA, Hennink WE. Polymer side-chain degradation as a tool to control the destabilization of polyplexes. Pharm Res. 2004;21:170-6. https://doi.org/10.1023/B:PHAM.0000012165. 68765.e6.

15. De Wolf HK, Luten J, Snel CJ, Storm G, Hennink WE. Biodegradable, cationic methacrylamide-based polymers for gene delivery to ovarian cancer cells in mice. Mol Pharm. 2008;5:349 57. https://doi.org/10.1021/mp700108r.

16. Samal SK, Dash M, Van Vlierberghe S, Kaplan DL, Chiellini E, van Blitterswijk C, et al. Cationic polymers and their therapeutic potential. Chem Soc Rev. 2012;41:7147-94. https://doi.org/10. 1039/c2cs35094g.

17. Cooper BM, Putnam D. Polymers for siRNA delivery: a critical assessment of current technology prospects for clinical application. ACS Biomater Sci Eng. 2016;2:1837-50. https://doi.org/10.1021/ acsbiomaterials.6b00363.

18. Scholz C, Wagner E. Therapeutic plasmid DNA versus siRNA delivery: common and different tasks for synthetic carriers. J Control Release. 2012;161:554-65. https://doi.org/10.1016/j.jconrel.2011. 11.014.

19. Suk JS, Xu Q, Kim N, Hanes J, Ensign LM. PEGylation as a strategy for improving nanoparticle-based drug and gene delivery. Adv Drug Deliv Rev. 2016;99:28-51. https://doi.org/10.1016/j. addr.2015.09.012.

20. Mickler FM, Vachutinsky Y, Oba M, Miyata K, Nishiyama N, Kataoka K, et al. Effect of integrin targeting and PEG shielding on polyplex micelle internalization studied by live-cell imaging. J Control Release. 2011;156:364-73. https://doi.org/10.1016/J. JCONREL.2011.08.003.

21. Takeda KM, Osada K, Tockary TA, Dirisala A, Chen Q, Kataoka K. Poly(ethylene glycol) crowding as critical factor to determine pDNA packaging scheme into polyplex micelles for enhanced gene expression. Biomacromolecules. 2017;18:36-43. https://doi.org/ 10.1021/acs.biomac.6b01247.

22. Williford J-M, Ren Y, Huang K, Pan D, Mao H-Q. Shape transformation following reduction-sensitive PEG cleavage of polymer/ DNA nanoparticles. J Mater Chem B. 2014;2:8106-9. https://doi. org/10.1039/C4TB00967C.

23. Verbaan FJ, Oussoren C, Snel CJ, Crommelin WE, Hennink WE, Storm G. Steric stabilization of poly(2-(dimethylamino)ethyl methacrylate)-based polyplexes mediates prolonged circulation and tumor targeting in mice. J Gene Med. 2004;6:64-75. https://doi.org/ 10.1002/jgm. 475 .

24. Blessing T, Kursa M, Holzhauser R, Kircheis R, Wagner E. Different strategies for formation of PEGylated EGF-conjugated PEI/DNA complexes for targeted gene delivery. Bioconjug Chem. 2001;12:529-37. https://doi.org/10.1021/bc0001488.

25. Lou B, De Beuckelaer A, Dakwar GR, Remaut K, Grooten J, Braeckmans K, et al. Post-PEGylated and crosslinked polymeric ssRNA nanocomplexes as adjuvants targeting lymph nodes with increased cytolytic $\mathrm{T}$ cell inducing properties. J Control Release. 2018;284:73-83. https://doi.org/10.1016/J.JCONREL.2018.06. 010.

26. Lachelt U, Wagner E. Nucleic acid therapeutics using polyplexes: a journey of 50 years (and beyond). Chem Rev. 2015;115:11043-78. https://doi.org/10.1021/cr5006793. 
27. Lee Y, Kataoka K. Biosignal-sensitive polyion complex micelles for the delivery of biopharmaceuticals. Soft Matter. 2009;5:3810. https://doi.org/10.1039/b909934d.

28. Kim HJ, Oba M, Pittella F, Nomoto T, Cabral H, Matsumoto Y, et al. PEG-detachable cationic polyaspartamide derivatives bearing stearoyl moieties for systemic siRNA delivery toward subcutaneous Bxpc3 pancreatic tumor. J Drug Target. 2012;20:33-42. https://doi. org/10.3109/1061186X.2011.632010.

29. Novo L, Rizzo LY, Golombek SK, Dakwar GR, Lou B, Remaut K, et al. Decationized polyplexes as stable and safe carrier systems for improved biodistribution in systemic gene therapy. J Control Release. 2014;195:162-75. https://doi.org/10.1016/j.jconrel.2014. 08.028 .

30. Lou B, Beztsinna N, Mountrichas G, van den Dikkenberg JB, Pispas S, Hennink WE. Small nanosized poly(vinyl benzyl trimethylammonium chloride) based polyplexes for siRNA delivery. Int J Pharm. 2017;525:388-96. https://doi.org/10.1016/j. ijpharm.2017.03.036.

31. Amar-Lewis E, Azagury A, Chintakunta R, Goldbart R, Traitel T, Prestwood J, et al. Quaternized starch-based carrier for siRNA delivery: from cellular uptake to gene silencing. J Control Release. 2014;185:109-20. https://doi.org/10.1016/j.jconrel.2014.04.031.

32. Liu L, Zheng M, Librizzi D, Renette T, Merkel OM, Kissel T. Efficient and tumor targeted siRNA delivery by polyethylenimine-graft-polycaprolactone-block-poly(ethylene glycol)-folate (PEI-PCL-PEG-Fol). Mol Pharm. 2016;13:134-43. https://doi.org/10.1021/acs.molpharmaceut.5b00575.

33. Kim HJ, Miyata K, Nomoto T, Zheng M, Kim A, Liu X, et al. SiRNA delivery from triblock copolymer micelles with spatiallyordered compartments of PEG shell, siRNA-loaded intermediate layer, and hydrophobic core. Biomaterials. 2014;35:4548-56. https://doi.org/10.1016/j.biomaterials.2014.02.016.

34. Lou B, De Koker S, Lau CYJ, Hennink WE, Mastrobattista E. mRNA polyplexes with post-conjugated GALA peptides efficiently target, transfect and activate antigen presenting cells. Bioconjug Chem. 2018;30:461-75. https://doi.org/10.1021/acs.bioconjchem. $8 \mathrm{~b} 00524$.

35. Oupický D, Koňák Č, Ulbrich K. DNA complexes with block and graft copolymers of $\mathrm{N}$-(2-hydroxypropyl)methacrylamide and 2(trimethylammonio)ethyl methacrylate. J Biomater Sci Polym Ed. 1999;10:573-90. https://doi.org/10.1163/156856299X00496.

36. Goddard-Borger ED, Stick RV. An efficient, inexpensive, and shelfstable diazotransfer reagent: imidazole-1-sulfonyl azide hydrochloride. Org Lett. 2007;9:3797-800. https://doi.org/10.1021/ ol701581g.

37. Moraes J, Simionca I-M, Ketari H, Klok H-A. Avoiding compositional drift during the RAFT copolymerization of $\mathrm{N}-(2$ hydroxypropyl)methacrylamide and $\mathrm{N}$-acryloxysuccinimide: towards uniform platforms for post-polymerization modification. Polym Chem. 2015;6:3245-51. https://doi.org/10.1039/ C5PY00253B

38. Heredia KL, Grover GN, Tao L, Maynard HD. Synthesis of heterotelechelic polymers for conjugation of two different proteins. Macromolecules. 2009;42:2360-7. https://doi.org/10.1021/ ma8022712.

39. Shi Y, van den Dungen ET a, Klumperman B, van Nostrum CF, Hennink WE. Reversible addition-fragmentation chain transfer synthesis of a micelle-forming, structure reversible thermosensitive diblock copolymer based on the $\mathrm{N}$-(2-hydroxy propyl) methacrylamide backbone. ACS Macro Lett. 2013;2:403-8. https://doi.org/10.1021/mz300662b.

40. Jiang X, van der Horst A, van Steenbergen MJ, Akeroyd N, van Nostrum CF, Schoenmakers PJ, et al. Molar-mass characterization of cationic polymers for gene delivery by aqueous size-exclusion chromatography. Pharm Res. 2006;23:595-603. https://doi.org/10. 1007/s11095-006-9574-4.
41. Nuhn L. Size-dependent knockdown potential of siRNA- loaded cationic nanohydrogel particles. Biomacromolecules. 2014;0033: 4111-21.

42. Johnston ALM, Lun X, Rahn JJ, Liacini A, Wang L, Hamilton MG, et al. The p75 neurotrophin receptor is a central regulator of glioma invasion. PLoS Biol. 2007;5:1723-37. https://doi.org/10.1371/ journal.pbio.0050212.

43. Kumar R, Conklin DS, Mittal V. High-throughput selection of effective RNAi probes for gene silencing. Genome Res. 2003;13: 2333-40. https://doi.org/10.1101/gr.1575003.

44. Naik RJ, Chandra P, Mann A, Ganguli M. Exogenous and cell surface glycosaminoglycans alter DNA delivery efficiency of arginine and lysine homopeptides in distinctly different ways. J Biol Chem. 2011;286:18982-93. https://doi.org/10.1074/jbc.M111. 227793.

45. Willcock H, O'Reilly RK. End group removal and modification of RAFT polymers. Polym Chem. 2010;1:149-57. https://doi.org/10. 1039/B9PY00340A.

46. Averick S, Mehl RA, Das SR, Matyjaszewski K. Well-defined biohybrids using reversible-deactivation radical polymerization procedures. J Control Release. 2015;205:45-57. https://doi.org/ 10.1016/j.jconrel.2014.11.030.

47. Ming W, Xiaofeng Z, Xiaojiao R, Bailiang Y, Long C, Feizhuan L, et al. Efficacy and safety of first-line chemotherapy plus bevacizumab in patients with metastatic colorectal cancer: a met. Chin Med J. 2014;127:538-46. https://doi.org/10.3760/cma.j.issn. 0366-6999.20132241.

48. Oba M, Miyata K, Osada K, Christie RJ, Sanjoh M, Li W, et al. Polyplex micelles prepared from $\omega$-cholesteryl PEG-polycation block copolymers for systemic gene delivery. Biomaterials. 2011;32:652-63. https://doi.org/10.1016/j.biomaterials.2010.09. 022.

49. Song Y, Lou B, Zhao P, Lin C. Multifunctional disulfide-based cationic dextran conjugates for intravenous gene delivery targeting ovarian cancer cells. Mol Pharm. 2014;11:2250-61. https://doi.org/ 10.1021/mp4006672.

50. Cherng JY, vandeWetering P, Talsma H, Crommelin DJA, Hennink WE. Effect of size and serum proteins on transfection efficiency of poly((2-dimethylamino)ethyl methacrylate)-plasmid nanoparticles. Pharm Res. 1996;13:1038-42. https://doi.org/10.1023/A: 1016054623543.

51. Luten J, Akeroyd N, Funhoff A, Lok MC, Talsma H, Hennink WE. Methacrylamide polymers with hydrolysis-sensitive cationic side groups as degradable gene carriers. Bioconjug Chem. 2006;17: 1077-84. https://doi.org/10.1021/bc060068p.

52. Shin S, Kim YS, Kim J, Kwon H-M, Kim D-E, Hah SS. Sniffing for gene-silencing efficiency of siRNAs in HeLa cells in comparison with that in HEK293T cells: correlation between knockdown efficiency and sustainability of sirnas revealed by FRET-based probing. Nucleic Acid Ther. 2013;23:152-9. https://doi.org/10. 1089/nat.2012.0396.

53. Hayashi K, Chaya H, Fukushima S, Watanabe S, Takemoto H, Osada K, et al. Influence of RNA strand rigidity on polyion complex formation with block catiomers. Macromol Rapid Commun. 2016;37:486-93. https://doi.org/10.1002/marc. 201500661

54. Danhier F, Le Breton A, Préat V. RGD-based strategies to target alpha(v) beta(3) integrin in cancer therapy and diagnosis. Mol Pharm. 2012;9:2961-73. https://doi.org/10.1021/ mp3002733.

55. Takemoto H, Miyata K, Ishii T, Hattori S, Osawa S, Nishiyama N, et al. Accelerated polymer - polymer click conjugation by freeze thaw treatment. Bioconjug Chem. 2012;23:1503-6.

56. Murray DW, Didier S, Chan A, Paulino V, Van Aelst L, Ruggieri R, et al. Guanine nucleotide exchange factor Dock7 mediates HGF- 
induced glioblastoma cell invasion via Rac activation. Br J Cancer. 2014;110:1307-15. https://doi.org/10.1038/bjc.2014.39.

57. Shayakhmetov DM, Eberly AM, Li Z-Y, Lieber A. Deletion of penton RGD motifs affects the efficiency of both the internalization and the endosome escape of viral particles containing adenovirus serotype 5 or 35 fiber knobs. J Virol. 2005;79:1053-61. https://doi. org/10.1128/JVI.79.2.1053-1061.2005.

58. Chávez A, Pujol M, Haro I, Alsina MA, Cajal Y. Membrane fusion by an RGD-containing sequence from the core protein VP3 of hepatitis A virus and the RGA-analogue: implications for viral in- fection. Biopolymers. 2001;58:63-77. https://doi.org/10.1002/ 1097-0282(200101)58:1<63::AID-BIP70>3.0.CO;2-L.

59. Alam MR, Ming X, Fisher M, Lackey JG, Rajeev KG, Manoharan $\mathrm{M}$, et al. Multivalent cyclic RGD conjugates for targeted delivery of small interfering RNA. Bioconjug Chem. 2011;22:1673-81. https://doi.org/10.1021/bc200235q.

Publisher's note Springer Nature remains neutral with regard to jurisdictional claims in published maps and institutional affiliations. 